ENVIRONMENTAL RESTORATION PROGRAM

\section{Treatability Study Operational Testing Program and Implementation Plan for the Gunite and Associated Tanks at the Oak Ridge National Laboratory, Oak Ridge, Tennessee}

MANAGED BY

LOCKHEED MARTIN ENERGY SYSTEMS, INC. FOR THE UNITED STATES DEPARTMENT OF ENERGY
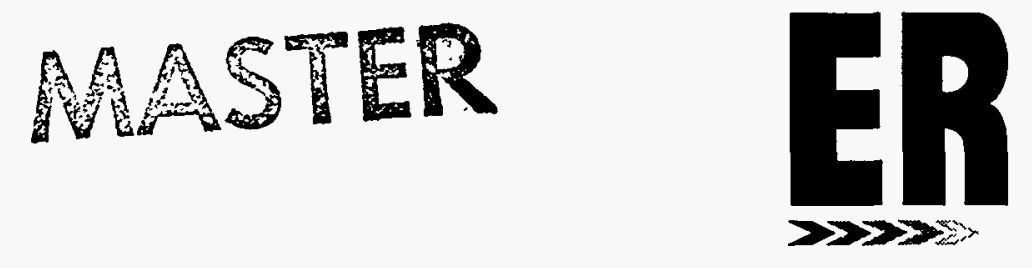


\section{Associates, Inc.}

contributed to the preparation of this document and should not be considered an eligible contractor for its review.

This report has been reproduced directly from the best available copy.

Available to DOE and DOE contractors from the Office of Scientific and Technical Information, P.O. Box 62, Oak Ridge, TN 37831; prices available from 423-576-8401 (fax 423-576-2865).

Available to the public from the National Technical Information Service, U.S. Department of Commerce, 5285 Port Royal Rd., Springfield, VA 22161. 


\section{PREFACE}

This report, Treatability Study Operational Testing Program and Implementation Plan for the Gunite and Associated Tanks at Oak Ridge National Laboratory, Oak Ridge, Tennessee, was developed under Work Breakdown Structure 1.4.12.6.1.01.41.12.03.05 (Activity Data Sheet 3301, "ORNL Treatability Studies for Gunite and Associated Tanks Operable Unit"). This document provides the Environmental Restoration Program with the guidelines for management and performance of the operational testing activities to be performed as part of the Gunite and Associated Tanks treatability study and remediation at ORNL. These activities clearly set forth a framework for writing operational procedures for system operation and data collection.

\section{DISCLAIMER}

This report was prepared as an account of work sponsored by an agency of the United States Government. Neither the United States Government nor any agency thereof, nor any of their employees, makes any warranty, express or implied, or assumes any legal liability or responsibility for the accuracy, completeness, or usefulness of any information, apparatus, product, or process disclosed, or represents that its use would not infringe privately owned rights. Reference herein to any specific commercial product, process, or service by trade name, trademark, manufacturer, or otherwise does not necessarily constitute or imply its endorsement, recommendation, or favoring by the United States Government or any agency thereof. The views and opinions of authors expressed herein do not necessarily state or reflect those of the United States Government or any agency thereof. 



\section{CONTENTS}

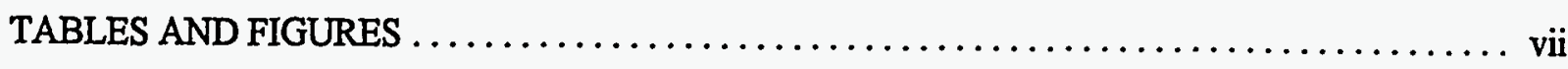

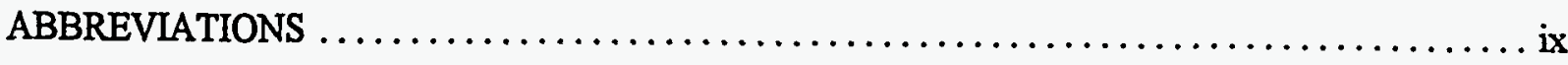

EXECUTIVE SUMMARY $\ldots \ldots \ldots \ldots \ldots \ldots \ldots \ldots \ldots \ldots \ldots \ldots \ldots \ldots \ldots \ldots \ldots \ldots \ldots \ldots$

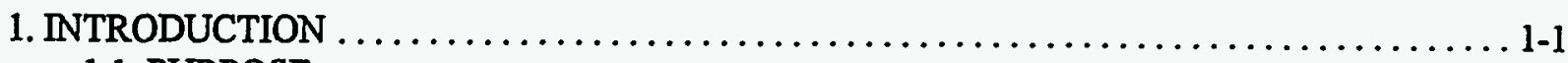

1.1 PURPOSE $\ldots \ldots \ldots \ldots \ldots \ldots \ldots \ldots \ldots \ldots \ldots \ldots \ldots \ldots \ldots \ldots \ldots \ldots \ldots \ldots \ldots \ldots, 1$

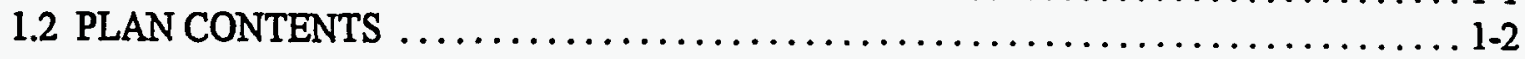

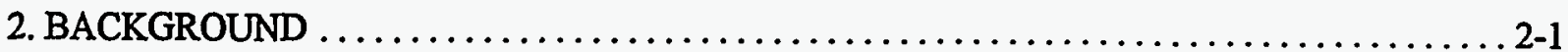

2.1 TANK HISTORY $\ldots \ldots \ldots \ldots \ldots \ldots \ldots \ldots \ldots \ldots \ldots \ldots \ldots \ldots \ldots, 2-1$

2.2 PROJECT HISTORY $\ldots \ldots \ldots \ldots \ldots \ldots \ldots \ldots \ldots \ldots \ldots \ldots \ldots \ldots \ldots \ldots \ldots \ldots \ldots \ldots, 2-1$

2.3 DQO CONCEPT $\ldots \ldots \ldots \ldots \ldots \ldots \ldots \ldots \ldots \ldots \ldots \ldots \ldots \ldots \ldots \ldots \ldots \ldots \ldots \ldots \ldots \ldots \ldots, 2-2$

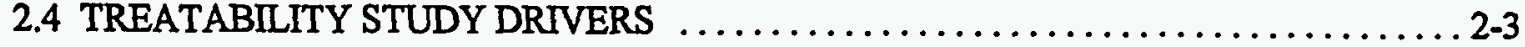

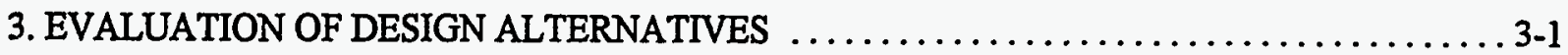

3.1 OFF-SITE CONFINED SLUICING END EFFECTOR DESIGN TESTS $\ldots \ldots \ldots \ldots \ldots .3-1$

3.1.1 Confined Sluicing End Effector Tests at UMR ................... 3-1

3.1.2 Prototype CSEE and Production Unit Acceptance Tests at PNNL ............ 3-2

3.2 OFF-SITE PROTOTYPE JET PUMP DESIGN TESTS $\ldots \ldots \ldots \ldots \ldots \ldots \ldots \ldots . . \ldots \ldots$

3.3 ON-SITE JET PUMP DESIGN TESTS $\ldots \ldots \ldots \ldots \ldots \ldots \ldots \ldots \ldots \ldots \ldots \ldots \ldots \ldots, 3$

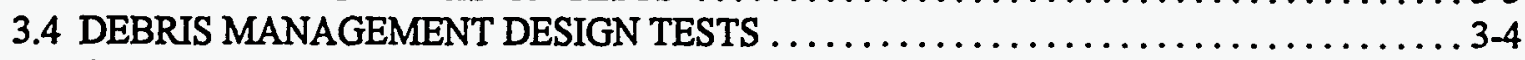

3.5 CAMERA AND LIGHTING DESIGN TESTS $\ldots \ldots \ldots \ldots \ldots \ldots \ldots \ldots \ldots \ldots \ldots \ldots \ldots$

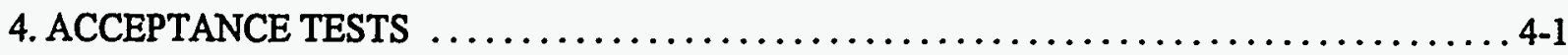

4.1 DECONTAMINATION SPRAY RING

AND TANK RISER INTERFACE CONTAINMENT BOX ACCEPTANCE TESTS .... . 4-1

4.2 WASTE DISLODGNG AND CONVEYANCE SYSTEM ACCEPTANCE TESTS $\ldots \ldots$.

4.3 MODIFIED LIGHT DUTY UTILITY ARM ACCEPTANCE TESTS $\ldots \ldots \ldots \ldots \ldots \ldots 4-2$

4.4 TRANSFER BOX ACCEPTANCE TESTS $\ldots \ldots \ldots \ldots \ldots \ldots \ldots \ldots \ldots \ldots \ldots .4,4$

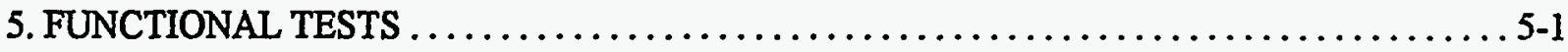

5.1 TRANSFER BOX FUNCTIONAL TESTS $\ldots \ldots \ldots \ldots \ldots \ldots \ldots \ldots \ldots \ldots \ldots \ldots, 1$

6. WASTE REMOVAL OPERATIONS IMPLEMENTATION ..................... 6-1

6.1 WASTE DISLODGING AND CONVEYANCE SYSTEM PERFORMANCE TESTS . . . 6-1

6.2 MODIFIED LIGHT DUTY UTILITY ARM PERFORMANCE TESTS $\ldots \ldots \ldots \ldots \ldots .6-5$

6.3 INTEGRATED SYSTEM PERFORMANCE TESTS $\ldots \ldots \ldots \ldots \ldots \ldots \ldots \ldots \ldots .6,8$

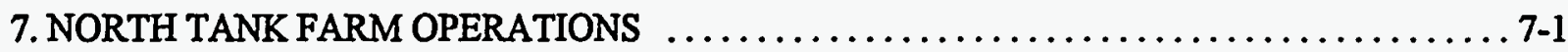

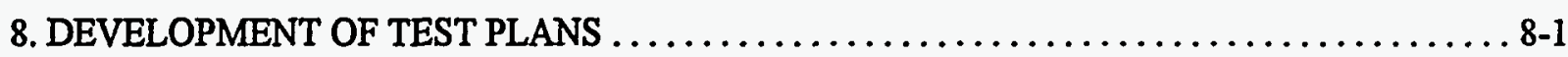

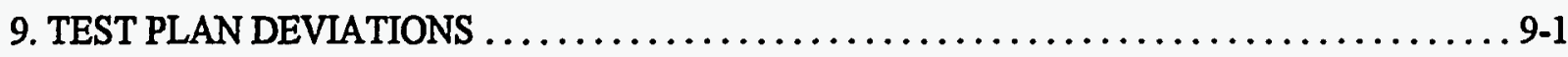


10. DATA MANAGEMENT AND QUALITY CONTROL $\ldots \ldots \ldots \ldots \ldots \ldots \ldots \ldots \ldots \ldots$ 10-1

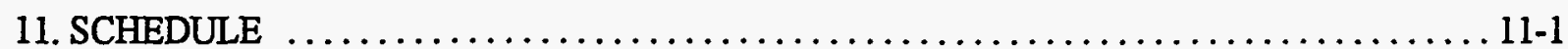

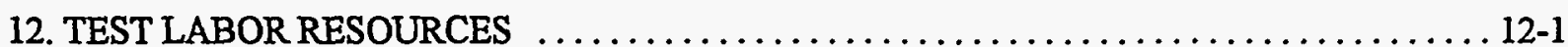

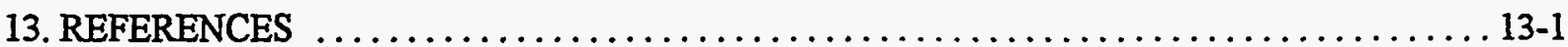




\section{FIGURES}

1. Operational testing matrix $\ldots \ldots \ldots \ldots \ldots \ldots \ldots \ldots \ldots \ldots \ldots \ldots \ldots \ldots \ldots \ldots \ldots \ldots \ldots \ldots \ldots$

\section{TABLES}

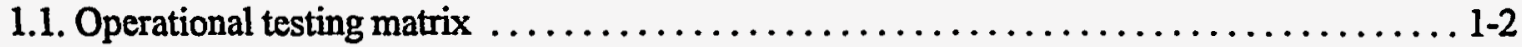

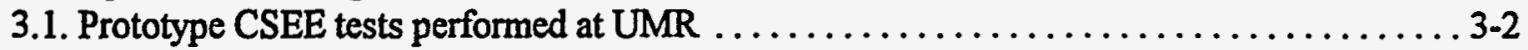

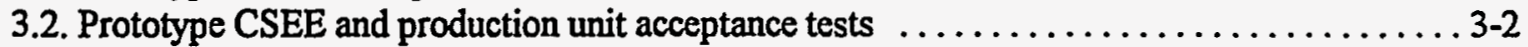

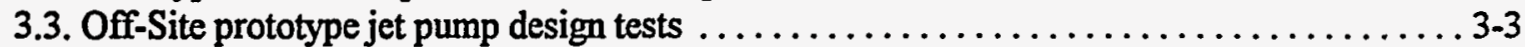

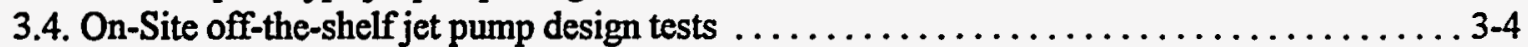

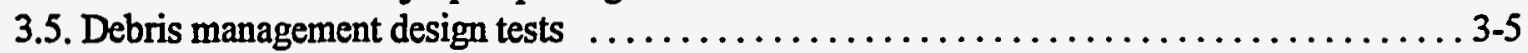

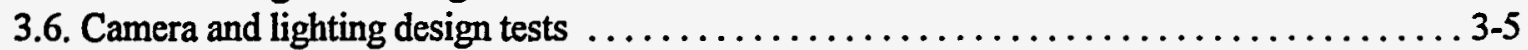

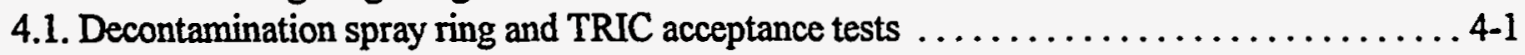

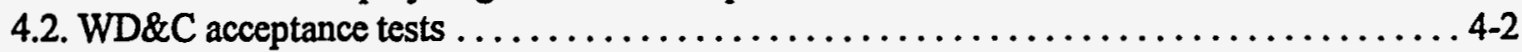

4.3. MLDUA acceptance tests . . . . . . . . . . . . . . . . .

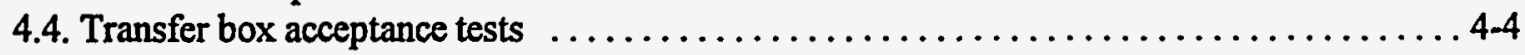

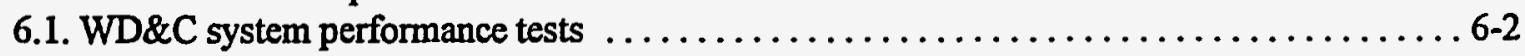

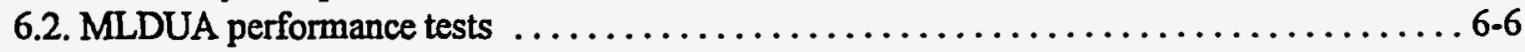

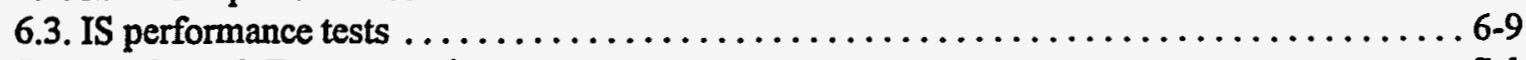

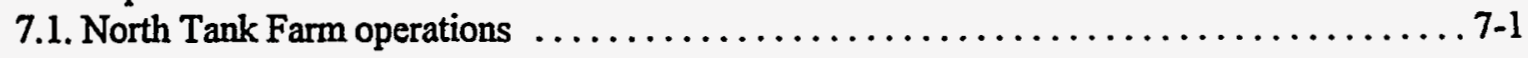




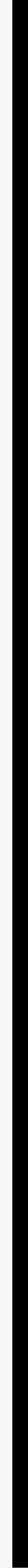




\section{ABBREVIATIONS}

$\begin{array}{ll}\text { ALARA } & \text { as low as reasonably achievable } \\ \text { BOP } & \text { balance of plant } \\ \text { CERCLA } & \text { Comprehensive Environmental Response, Compensation, and } \\ & \text { Liability Act } \\ \text { confined sluicing end effector } \\ \text { CSEE } & \text { U.S. Department of Energy } \\ \text { DOE } & \text { data quality objective } \\ \text { DQO } & \text { Lockheed Martin Energy Systems } \\ \text { Energy Systems } & \text { U.S. Environmental Protection Agency } \\ \text { EPA } & \text { feasibility study } \\ \text { FS } & \text { Gunite and Associated Tanks } \\ \text { GAAT } & \text { high efficiency particulate air } \\ \text { HEPA } & \text { hose management system } \\ \text { HMS } & \text { hydraulic test bed } \\ \text { HTB } & \text { integrated system (MLDUA and WD\&C systems working together) } \\ \text { IS } & \text { Los Alamos Technical Associates, Inc. } \\ \text { LATA } & \text { light duty utility arm } \\ \text { LDUA } & \text { modified light duty utility arm } \\ \text { MLDUA } & \text { North Tank Farm } \\ \text { NTF } & \text { Oak Ridge National Laboratory } \\ \text { ORNL } & \text { operable unit } \\ \text { OU } & \text { Pacific Northwest National Laboratory } \\ \text { PNNL } & \text { personal protective equipment } \\ \text { PPE } & \text { remedial action } \\ \text { RA } & \text { Spar Aerospace Limited } \\ \text { SPAR } & \text { South Tank Farm } \\ \text { STF } & \text { Tennessee Department of Environment and Conservation } \\ \text { TDEC } & \text { tank riser interface containment } \\ \text { TRIC } & \text { treatability study } \\ \text { TS } & \text { Tanks Technology Cold Test Facility } \\ \text { TTCTF } & \text { University of Missouri at Rolla } \\ \text { UMR } & \text { waste dislodging and conveyance } \\ \text { WD\&C } & \end{array}$





\section{EXECUTIVE SUMMARY}

This Treatability Study (TS) Operational Testing Program and Implementation Plan identifies operational testing to be performed to:

(1) Demonstrate the technical feasibility of methods proposed for the removal of radiochemical sludge heels from the underground storage tanks located at Oak Ridge National Laboratory (ORNL), known as the Gunite and Associated Tanks (GAAT) Operable Unit (OU). (The bulk of the radiochemical waste, which was previously stored in the tanks, was removed during the 1980 s, and only a sludge heel remains.)

(2) Reduce the uncertainty in meeting the Comprehensive Environmental Response, Compensation, and Liability Act (CERCLA) requirements for the GAAT OU.

(3) Minimize the overall costs to accomplish the first two objectives.

An initial Feasibility Study (FS) effort identified uncertainties in the evaluation of various alternatives for addressing the remediation of the GAAT OU. To support future decision making, the U.S. Department of Energy is performing a TS to identify cost-effective remediation approaches for the GAAT OU by providing information to reduce cost and technical uncertainty and better define acceptable remediation strategies.

The testing activities will be initially conducted in a nonradioactive environment at the Tanks Technology Cold Test Facility (TTCTF) at ORNL. This will permit the design and initial performance testing and training activities to be completed while minimizing the risk, employee exposure, and costs associated with the testing effort. The component design and functional testing and initial system performance testing will be completed in the TTCTF. After the component and initial system performance testing have been completed, the operations testing will continue in the North Tank Farm (NTF). This testing has an associated higher cost and risk, but is necessary to provide results for actual waste heel removal.

A technique known as confined sluicing, which uses a high-pressure $(>3,000 \mathrm{psi})$, low-volume water jet waste dislodging tool integrated with a jet pump for waste conveyance, was selected for the TS. The TS operational testing activities are focused on demonstrating the ability of confined sluicing technology to remove radiochemical sludge heels from the gunite tanks and on developing information to provide answers to CERCLA requirements, including estimating the cost to implement waste removal activities. The TS testing activities will be performed intermittently over approximately 20 months, November 1995 through June 1997. The TS will include the following stages:

- Tests to support the evaluation of design alternatives and mining strategy development,

- Equipment and instrumentation acceptance and functional tests,

- Waste Dislodging and Conveyance System performance tests,

- Modified Light Duty Utility Arm performance tests,

- Integrated System performance tests,

- NTF operations, and 

- Data analysis and CERCLA requirement uncertainty reduction.

The desired outcome of the TS Operational Testing Program and Implementation Plan is to establish guidelines for management and performance of the operational testing activities that clearly set forth a framework for writing operational procedures for operation and data collection. Each testing stage is designed to build upon results of the previous testing stage(s).

The location for each testing stage has been selected because of availability and convenience, as well as to provide the most information and working knowledge of the equipment for the personnel who will be operating the equipment, at the least cost to the project. In general, the earlier in the testing program that tests can be performed, the less the testing will cost (i.e., performance testing in a "cold" test facility will cost less than "hot" testing in the NTF) (see Fig. 1). Testing of the field deployment and operations of the developmental waste removal systems will be performed in the NTF, where the lower contaminant inventory presents less risk to workers and the environment than in the South Tank Farm.

The (nonradioactive) operational testing will accomplish several critical goals in gaining knowledge of the system before tank farm operations begin:

- Establish and demonstrate desired operating and safety envelopes for equipment;

- Provide training of operations personnel;

- Allow testing, revision, and finalization of operating, sampling, maintenance, installation, and equipment transport procedures;

- Provide documentation for Readiness Assessment review of the operating system and operations personnel;

- Provide information to estimate personnel exposures for activities during tank farm operations;

- Develop mining strategies to define sludge removal techniques to be used for varying sludge compositions; and

- Provide a portion of the information on the cost, implementability, and effectiveness of the confined sluicing technology for input to the FS process. However, the NTF testing will provide most of the cost information.

Individual test procedures will be developed to define each operational test and to establish preliminary conditions, safety precautions, sequencing, and acceptance criteria for completing each test. The test procedures will more completely define the tests to be performed, the parameters to be measured, and the test data to be collected.

To ensure that the operational testing program remained streamlined and focused on the necessary collection of data and information, the testing requirements have been developed from the questions prepared by, and discussions among, GAAT team members in applying the Data Quality Objective (DQO) process. The DQO process should be used repeatedly during the life cycle of a project to optimize the design.

The document is intended to be a "living document" and as such, certain portions (such as schedule) may change during the execution of the operational testing activities. 
!!̣x
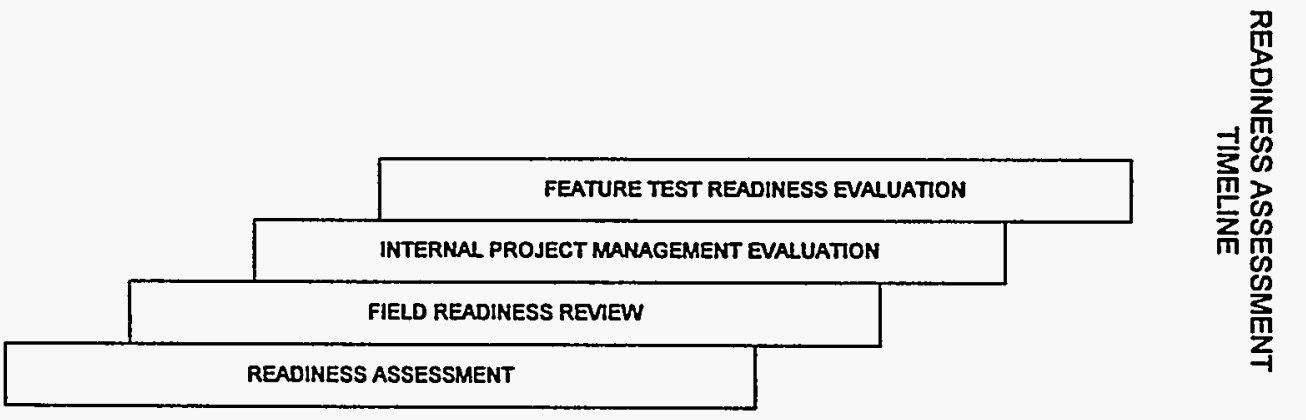


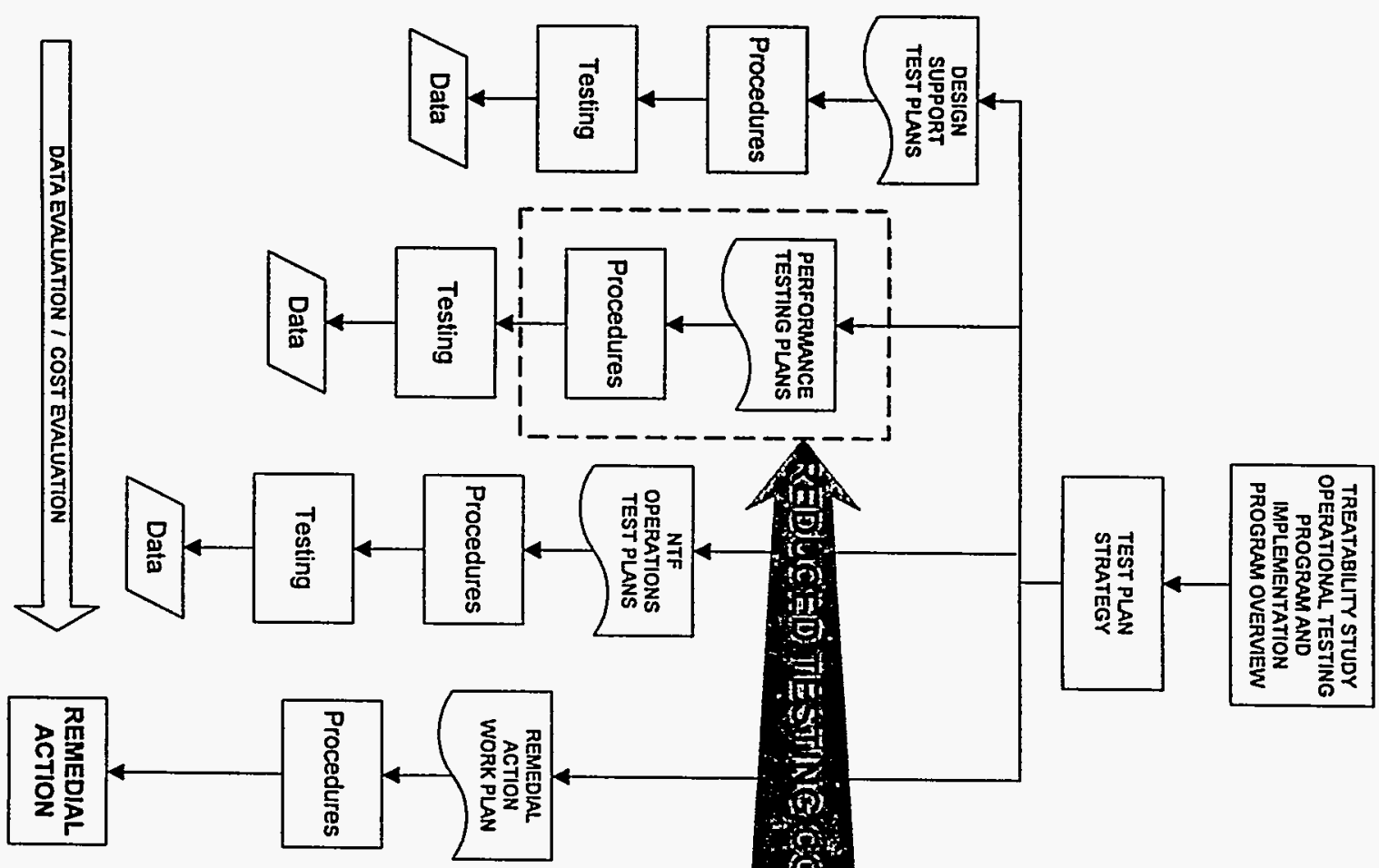

คุ

\begin{tabular}{l}
$\infty$ \\
71 \\
8 \\
717 \\
0 \\
\hdashline
\end{tabular}

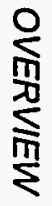

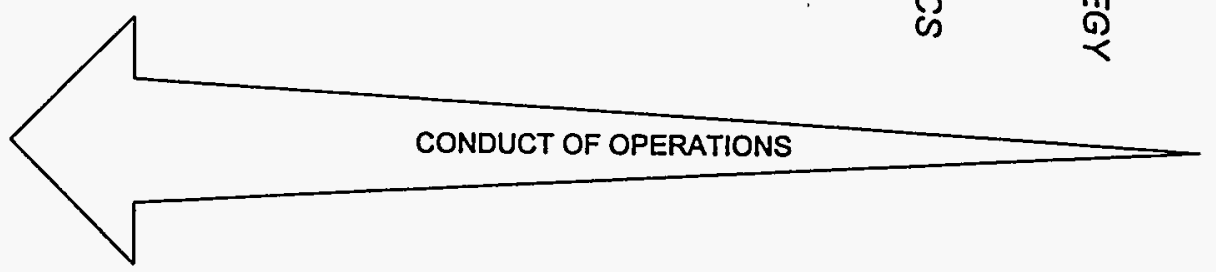




\section{INTRODUCTION}

To support future decision making of the Gunite and Associated Tanks (GAAT) Operable Unit (OU) remedy selection, the Department of Energy (DOE) is performing a Treatability Study (TS), consistent with the U.S. Environmental Protection Agency (EPA) guidance for Comprehensive Environmental Response, Compensation, and Liability Act (CERCLA) treatability studies (EPA 1992). The study will inform stakeholders [DOE, EPA, Tennessee Department of Environment and Conservation (TDEC), and the public] about various waste removal technologies and the cost of potential remediation approaches, particularly the cost associated with sluicing and the reduction in risk to human health and the environment from tank content removal. As part of the GAAT OU remedy, a series of studies and technology tests will be performed. These may address one or more of the following areas: characterization, removal, treatment, and transfer of wastes stored in the GAAT OU.

An initial feasibility study (FS) effort in 1994 identified uncertainties in the evaluation of various alternatives for the GAAT site. This TS operational testing program outlines the tests planned to reduce uncertainties and to demonstrate the technical feasibility of methods proposed for the removal of radioactive wastes from these underground storage tanks.

\subsection{PURPOSE}

The objective of the GAAT TS Operational Testing Program and Implementation Plan is to develop a planned approach to TS testing activities.

The TS operational testing activities are focused on testing the ability of confined sluicing technology to remove radiochemical sludge heels from the gunite tanks and on developing information to provide answers to CERCLA requirements, including estimating the cost to implement waste removal activities. The TS testing activities will be performed intermittently over a period of approximately 20 months, November 1995 through June 1997. The TS will include the following stages of testing:

- tests to support the evaluation of design alternatives and mining strategy development,

- equipment and instrumentation acceptance and functional tests,

- Waste Dislodging and Conveyance (WD\&C) system performance tests,

- Modified light duty utility arm (MLDUA) performance tests,

- Integrated system (IS) performance tests, and

- North Tank Farm (NTF) operations.

The desired outcome of the TS Operational Testing Program Implementation Plan is to establish guidelines for management and performance of the operational testing activities. Each stage of testing will build on results of the previous testing stage(s). The location for each stage of testing has been selected because of convenience and availability, and to provide the most information and working knowledge of the equipment for the personnel who will be operating the equipment, at the least cost to the project. Table 1.1 provides a matrix of the testing to be performed that indicates the progression of testing from design support through NTF operations. 
Table 1.1. Operational testing matrix

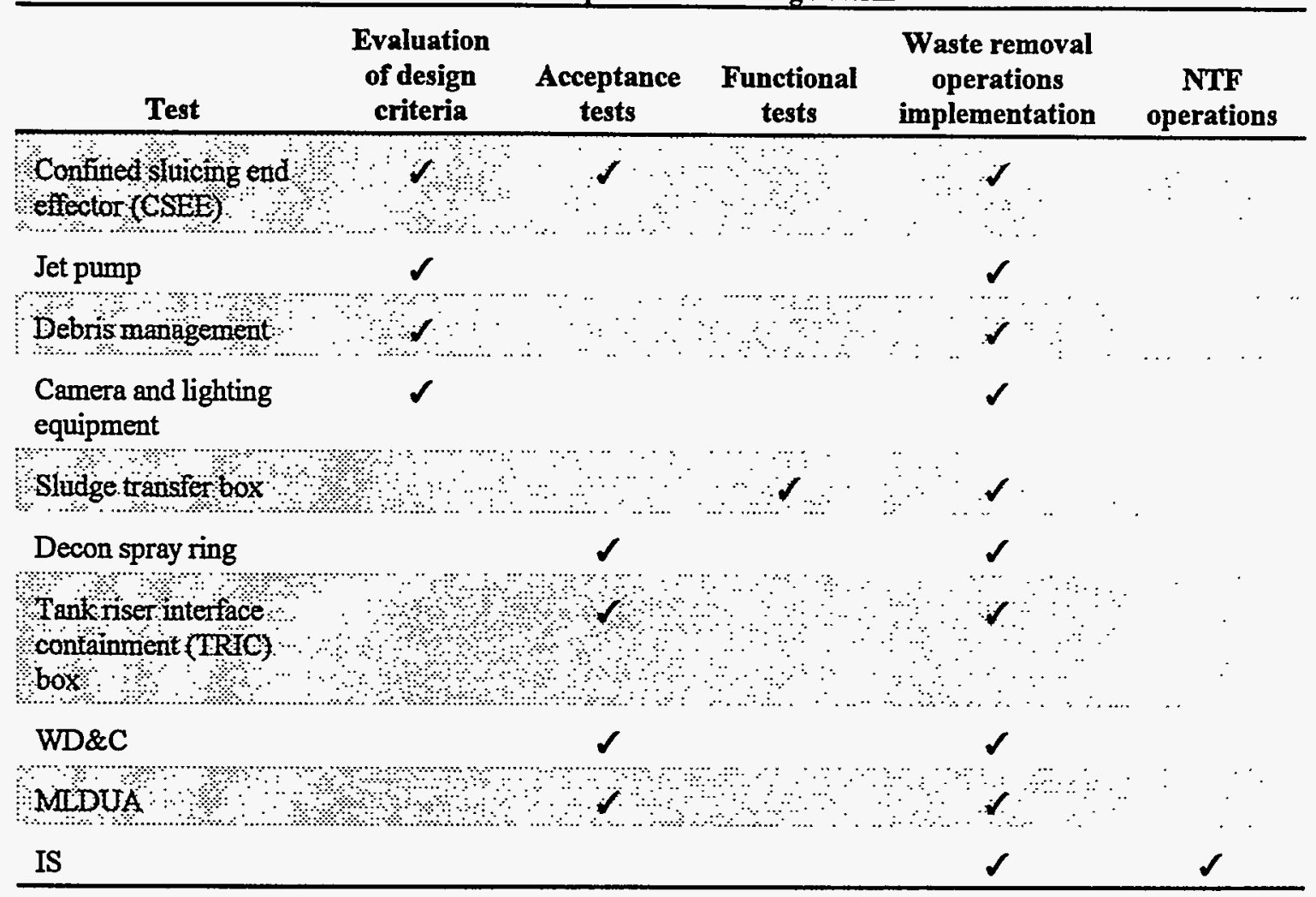

This plan defines what (scope), why, when, and where testing will be performed. Individual test plans and procedures will be developed based on this plan to provide detailed definition of each operational test and to establish procedures for completing each test. Sect. 8 provides additional information on the test plans to be developed.

\subsection{PLAN ORGANIZATION}

This plan consists of the following sections:

1. INTRODUCTION : This section introduces the purpose of the testing program and the plan's organization.

2. BACKGROUND: This section explains the GAAT tank history, the regulatory history for the project, and the development of the testing program requirements.

3. EVALUATION OF DESIGN ALTERNATIVES: This section addresses testing to be performed to evaluate design alternatives for equipment and instrumentation. This testing is performed at off-site locations and at Oak Ridge National Laboratory (ORNL). 
4. ACCEPTANCE TESTS: This section addresses testing to verify compliance of purchased components with performance specifications. The acceptance testing is to be performed at the component fabrication facility before delivery to ORNL. The functional testing will be performed on equipment following delivery to the ORNL Tanks Technology Cold Test Facility (TTCTF).

5. FUNCTIONAL TESTS: This section addresses testing to be performed on equipment following delivery to the ORNL TTCF. The TTCTF will be used to test the equipment in an environment to simulate a gunite tank, with an adjacent observation platform. Surrogate sludge of varying densities will be used to test the ability of the individual components to operate under conditions anticipated in the gunite tanks.

6. WASTE REMOVAL OPERATIONS IMPLEMENTATION: This section addresses testing to be performed at ORNL to verify that the WD\&C, the MLDUA, and the IS are operating as designed during waste retrieval operations. These tests shall be performed with surrogate sludge of varying densities and compositions.

7. NTF OPERATIONS: This section addresses testing of the confined sluicing technology to remove waste from two gunite tanks, W-3 and W-4, located in the GAAT NTF. These tanks were selected for the TS because their lower contaminant inventories presents less risk to workers and the environment for the first field deployment of the developmental waste removal systems. Testing on these tanks will generate data under actual field conditions to support the CERCLA FS process in determining the appropriate remedial action ( $\mathrm{RA}$ ) for implementation. If a removal action is selected for the GAAT South Tank Farm (STF), the NTF operations will provide the opportunity to implement system operational procedures before entering the STF, which is categorized as a nuclear facility.

8. DEVELOPMENT OF TEST PLANS AND PROCEDURES: This section addresses the next stage of the testing program, which is the development of individual test plans and procedures for each stage of testing.

9. TEST PLAN DEVIATIONS: This section defines the steps to be followed in the event that new tests are identified, planned tests are modified or deleted, or certain tests are not possible to implement.

10. DATA MANAGEMENT: This section describes data management requirements, including data collection, recording, evaluation and reporting.

11. SCHEDULE: This section presents the testing program schedule.

12. RESOURCES: This section presents an overview of resource requirements for implementation of the testing program.

13. REFERENCES: This section lists the references for the document. 


\section{-}




\section{BACKGROUND}

Background information explaining the development of the GAAT project leading up to the testing program is presented in this section.

\subsection{TANK HISTORY}

To collect, neutralize, and store radiochemical and other wastes, 12 underground storage tanks were constructed using an in-place gunite construction process. The tanks were constructed using an aggregate-free concrete (gunite) that was sprayed in layers onto rebar skeletons to form the tanks in place. Built in the 1940s, the gunite underground storage tanks have since been removed from service because of age and changes in liquid waste system needs and requirements. These tanks, along with four nearby stainless steel units, are known as the GAAT.

The bulk of the radiochemical waste sludge previously contained in the tanks was removed during the 1980s using hydraulic sluicing techniques. However, a waste "heel" of sludge, typically 6 to 8 in. deep, remains to be removed. The waste heel consists of a range of sludge types from soft, fluid sludge to less fluid, crystalline material and can include debris such as piping, steel tape, sampling equipment, and lengths of chain link. Maximum sludge depths in the tanks range up to $1.4 \mathrm{ft}$ with radiation levels greater than $50 \mathrm{rad} / \mathrm{h}$ at the waste surface. Except for W-7, each underground storage tank also has a supernate level above the sludge layer. The height of the supernate varies from inches to several feet in the underground storage tanks. Tank W-7 contains only pools of supernate liquid (DOE 1995).

\subsection{PROJECT HISTORY}

The CERCLA Remedial Investigation/FS process uses. a phased investigative approach to evaluating alternatives for addressing site remediation. Frequently, technologies have not been sufficiently demonstrated or characterization of the waste alone is insufficient to estimate the resources required to implement an action. When technology performance is difficult to predict, testing of the actual process may be the only means of obtaining the necessary information. Treatability testing is used to adequately evaluate performance, to provide design information, and to estimate costs in sufficient detail to support the remedy selection process.

During the preparation of the initial GAAT FS in 1994, DOE, EPA, and TDEC agreed that a CERCLA TS offered the opportunity to identify effective remediation approaches for the GAAT by providing information to reduce cost and technical uncertainty and to better define acceptable RA strategies. This plan has been developed to provide the framework for conducting technology tests and for collecting information in the areas of characterization, removal, conveyance, treatment, transfer, and stabilization of wastes stored in the GAAT OU. This operational testing program outlines the tests planned to demonstrate the technical feasibility of methods proposed for the removal of radioactive wastes from these underground storage tanks.

Under the auspices of the TS, a technique known as confined sluicing, which uses a high-pressure, low-volume water jet integrated with a jet pump, will be demonstrated and thoroughly evaluated. The confined sluicing approach to be tested during the TS consists of three primary systems: 1) the WD\&C system, which performs the waste removal operations; 2) the MLDUA, which positions and manipulates the WD\&C suction hose to achieve full tank coverage; and 3) the balance-of-plant (BOP) and control 
system, which directs and integrates the activities of the WD\&C and the MLDUA as well as auxiliary components, such as the viewing, containment, decontamination, high efficiency particulate air (HEPA) filtration and waste conveyance piping and equipment systems.

The resulting data from the GAAT TS will be used to complete the FS and support the final closure of the STF. The end goal of the GAAT TS is to document the evidence necessary to propose and defend a reliable and cost-effective remediation strategy for the gunite tanks (Energy Systems 1995).

\subsection{DATA QUALITY OBJECTIVE (DQO) CONCEPT}

To develop the GAAT TS Operational Testing Program, the DQO process was applied. The DQO process is a planning tool for defining data needs in the CERCLA process. The DQO process is a series of planning steps designed to ensure that the type, quantity, and quality of data used in the CERCLA decision making process are appropriate for the intended application.

DQOs are qualitative and quantitative statements derived from the outputs of each step of the DQO process that:

1. Clarify the study objective,

2. Define the most appropriate type of data to collect,

3. Determine the most appropriate conditions from which to collect the data, and

4. Specify acceptable levels of decision errors that will be used as the basis for establishing the quantity and quality of data needed to support the decision.

The DQOs are then used to develop a scientific and resource-effective testing program.

The DQO process should be used repeatedly during the life cycle of a project. Early in a project, a more preliminary and qualitative application of the DQO process may be appropriate to meet the project's needs. As more details and decisions about the site develop, a more thorough and quantitative application of the DQO process is usually warranted.

The DQO process has been applied by the GAAT team members to define requirements for data collection during the GAAT TS. Using each of the TS drivers (Sect. 2.4) as a basis for developing data needs, the DQO approach was employed and includes the following steps for the GAAT operational testing program:

1. State the objectives. The operational testing program objectives are to collect information on the performance of the confined sluicing system in meeting the CERCLA criteria.

2. Identify the questions to be answered by the testing program.

3. Identify the data requirements needed to answer the questions.

4. Define the study boundaries. The operational testing program study boundaries are determined by the stages of testing the confined sluicing technology: evaluation of design, acceptance tests, functional tests, subsystem performance tests, and the NTF operations. 
5. Define the testing to be performed, within the study boundaries, to collect the data required to answer the questions.

6. Specify acceptable limits on decision errors. Once defined, the limits on decision errors are used to establish performance goals (such as an acceptable instrument accuracy) to limit uncertainty in the data collected.

7. Optimize the system design to generate the most resource-effective testing program.

To develop the data needs for the operational testing program and RA process, story boards of the baseline TS and RA activities was developed. The story boards were used to define, or state, the objectives. After the story boards were developed, the questions to be answered by the operational testing program (item 2 above) and the data needed to answer those questions (item 3 above) were developed and compiled into a database (Appendix A).

Some questions identified during this process do not need additional data to be answered, but require evaluation and manipulation of existing data. Also, some questions will not be answered directly by data collected during the operational testing program but will require evaluation and manipulation of data to be collected during the testing. These questions have been categorized in the database as: existing data, pre-NTF operations, and pre-RA data requirements. Additional data that will provide valuable information for the FS process will be collected from other GAAT activities, including the evaluation of segregation and treatment options. These additional activities also comply with the DQO process in their data development.

The database presented in Appendix A allows the manipulation and sorting of the questions and data requirements in many different ways. For planning the testing program, the database was sorted according to the testing schedule established for the process systems (item 4 above).

Following evaluation of all the requirements for data to be collected during the operational testing program, the individual test requirements have been defined (item 5 above), as presented in Sects. 3 through 7 of this document. The data requirements listed in Appendix A form the basis for the test requirements.

The remaining steps of the DQO process, to specify limits on decision errors (item 6 above) and to optimize the design to generate the most resource-effective testing program (item 7) will be performed during the preparation of the individual test plans for each piece of equipment. These steps are described further in Sect. 8.

\subsection{TS DRIVERS}

The TS is designed to support future decision making in the remedy-selection process for the GAAT OU. Specific information to be gathered during the GAAT operational testing activities includes:

- confined sluicing's ability to meet CERCLA threshold criteria;

- cost and effectiveness of tank-content removal by confined sluicing; and

- operational safety information to be incorporated in the remediation procedures.

Additional information to support the remedy-selection process includes data collected from other GAAT activities, such as the evaluation of tank content segregation and treatment options. 
. 


\section{EVALUATION OF DESIGN ALTERNATIVES}

Testing of equipment and instrument components is needed to verify and support:

- design and subsequent modifications (if required) of the individual components;

- design of the components as an IS; and

- development of a mining strategy to be used in tank cleaning operations.

This section defines testing that either has been performed, or is yet to be performed to provide information to support these functions. The design testing that has been completed to date includes:

- testing of the prototype confined sluicing end effector (CSEE) at the University of Missouri at Rolla (UMR)

- testing of a prototype jet pump and transfer pipe run at UMR, and

- testing of a jet pump and mock hose management system (HMS) at ORNL.

Further design testing is planned for the prototype CSEE (designed and tested at UMR) at Pacific Northwest National Laboratory (PNNL), and for the development of debris management processes at ORNL.

The DOE EM-50 program has provided the necessary funding for the testing to support the design of the CSEE at UMR and PNNL, and the testing to support the design of the jet pump at UMR. The remaining testing is supported by the DOE EM-40 program.

The tests to support the evaluation of design alternatives are described in the following sections. The tables in the following sections identify the individual "tests" and the "objectives" of those tests to be performed for each major piece of equipment in the system. Specific data requirements for each test will be identified in the development of the test plans for each test prepared in accordance with Sect. 7 .

\subsection{OFF-SITE CSEE DESIGN TESTS}

UMR has evaluated the design parameters of an effective CSEE to determine a prototype CSEE design for the GAAT OU remediation. UMR will specify the CSEE design and will provide PNNL with a prototype model of the CSEE for further evaluation by PNNL at their Hydraulic Test Bed (HTB) testing facility. Testing at PNNL will be performed to support the detailed design of the CSEE to be used in the tank farm operations and to support the development of a mining strategy.

The tests are to be funded by EM-50 with input and support by the GAAT TS project team.

\subsubsection{CSEE Tests at UMR}

UMR has been performing tests to provide a prototype CSEE design. The testing has resulted in the design of a prototype unit that meets the design parameters established in the testing, such as nozzle angles, nozzle size, and CSEE dimensions within a limited weight budget. Once UMR has finalized the conceptual design, PNNL will prepare a detailed design and arrange fabrication of the unit. 
Specific tests and the objectives of each test to be performed at UMR are listed in Table 3.1. Test results are being used to optimize the end effector's final configuration, design, and operational procedures. Following CSEE optimization by UMR, UMR will provide PNNL with a prototype CSEE for testing in PNNL's HTB testing facility.

Table 3.1. Prototype CSEE tests performed at UMR

\begin{tabular}{|c|c|}
\hline Test & Objectives \\
\hline Sludge cleaning & $\begin{array}{l}\text { Define effective end effector design parameters for waste heel removal. These } \\
\text { parameters include nozzle angles, nozzle size and CSEE dimensions. Define } \\
\text { CSEE configuration within required CSEE weight budget }\end{array}$ \\
\hline $\begin{array}{l}\text { Concrete cleaning/ } \\
\text { scarifying }\end{array}$ & $\begin{array}{l}\text { Define effective end effector design parameters for tank wall and floor } \\
\text { cleaning and scarifying. These parameters include nozzle angles, nozzle size } \\
\text { and CSEE dimensions }\end{array}$ \\
\hline Force/torque & $\begin{array}{l}\text { Determine the forces, torques, and frequency spectrum generated at the tool } \\
\text { interface plate of the manipulator arm resulting from variations in CSEE } \\
\text { design parameters such as nozzle size, nozzle angle, rotating speed, etc. }\end{array}$ \\
\hline MLDUA compatibility & $\begin{array}{l}\text { Verify that the CSEE can be used in conjunction with the MLDUA to include } \\
\text { the following requirements: } \\
\text { - CSEE dimensions } \\
\text { - Weight budget } \\
\text { - Mobility } \\
\text { - Force/torque loads }\end{array}$ \\
\hline
\end{tabular}

\subsubsection{Prototype CSEE and Production Unit Acceptance Tests at PNNL}

The prototype model provided to PNNL by UMR will be tested with simulated sludge to finalize the detailed design parameters for tank cleaning operations and define an efficient and effective envelope of operating parameters for the CSEE. Operating parameters to be tested include water pressures and flow rates, nozzle rotation speed, and CSEE stand-off distances. Data collected from this effort will be used to prepare the final design and fabricate the CSEE.

The selected CSEE design will be tested for acceptance by ORNL at this time to minimize test costs and efforts. The acceptance tests shall verify the operation of the selected production unit as required. Information collected from these tests will also be used to support the development of tank mining strategies. Specific tests and the objectives of each test are listed in Table 3.2.

Table 3.2. Prototype CSEE and production unit acceptance tests

Test

Sludge cleaning

Concrete cleaning and scarifying
Objectives

Define the effective operating parameters and the desired operating envelope for waste heel removal and sludge cleaning. Parameters include water pressures and flow rates and nozzle rotation speed. Define intake wiper or screen for minimization of potential for line plugging

Define the effective operating parameters and the desired operating envelope for tank wall and floor cleaning and scarifying. Parameters include water pressures and flow rates and nozzle rotation speed 
Table 3.2 (continued)

\begin{tabular}{ll}
\hline \multicolumn{1}{c}{ Test } & \multicolumn{1}{c}{ Objectives } \\
\hline CSEE stand-off & $\begin{array}{l}\text { Define the CSEE effectiveness at varying distances from a sludge surface } \\
\text { and from a tank floor }\end{array}$ \\
MLDUA & $\begin{array}{l}\text { Verify that the CSEE can be used in conjunction with the MLDUA with } \\
\text { respect to force/torque loading }\end{array}$ \\
\hline
\end{tabular}

\subsection{OFF-SITE PROTOTYPE JET PUMP DESIGN TESTS}

A jet pump will be used in the tank farm operations to provide a suction lift and transfer of the tank contents from the GAAT tanks. In testing the specific jet pump design parameters that can be varied, UMR has tested the operation of a prototype jet pump, Mark IV, with a simulated sludge. This testing has been funded by EM-50. Specific jet pump tests and the objectives of each test are listed in Table 3.3.

Table 3.3. Off-Site prototype jet pump design tests

\begin{tabular}{ll}
\hline \multicolumn{1}{c}{ Test } & \multicolumn{1}{c}{ Objectives } \\
\hline $\begin{array}{l}\text { Operational testing with } \\
\text { variation in line size }\end{array}$ & $\begin{array}{l}\text { Demonstrate for } 1 \frac{1}{2}-, \text {, 2-, and 3-in. line sizes: } \\
\text { discharge pressure and velocity characteristics, and } \\
\text { sludge settling characteristics within the line }\end{array}$ \\
$\begin{array}{l}\text { Debris } \\
\begin{array}{l}\text { Operational testing with } \\
\text { variations in sludge density }\end{array}\end{array}$ & $\begin{array}{l}\text { Determine maximum sludge density pumpable with jet pump operation } \\
\text { alone (no cutting jets) }\end{array}$ \\
\hline
\end{tabular}

Test results have been used to define pump design and system piping requirements for the TS system. Specifically, the off-site tests have been used to support the selection of WD\&C HMS line sizes and to support the design configuration of the jet pump to be fabricated for use in the tank farm operations.

\subsection{ON-SITE JET PUMP DESIGN TESTS}

An off-the-shelf jet pump with a mock HMS and supporting arm has been tested with simulated sludge at the TTCTF. Specific jet pump tests and the objectives of each test are listed in Table 3.4. These tests have provided the test team with information on the forces and torques that the WD\&C system and MLDUA may see during tank farm operations. This information will confirm the WD\&C functional requirements (e.g., whether the WD\&C HMS should be passive and led by the MLDUA or whether the joints on the WD\&C HMS should be driven).

In the development of the test plan for this on-site jet pump testing, review by the Lockheed Martin Energy Systems (Energy Systems) High Pressure Committee was performed. Performance of this health and safety function will result in several benefits to the testing program, including:

1. Early definition of high pressure design and operating requirements that will be enforced throughout the testing program, and

2. Early introduction of the health and safety personnel and the High Pressure Committee personnel to the testing operations to be performed at ORNL over the next year. 
Performance of this testing also provided an opportunity to:

1. Develop and prepare the cold testing facility to a state of readiness for jet pump operations and surrogate sludge transfer operations (prior to the actual testing);

2. Provide experience to testing personnel in operating this one component of the confined sluicing system, before the jet pump is integrated into the WD\&C system;

3. Define a preliminary surrogate sludge to be used in the testing activities, including defining the material source and material handling and transport requirements for the sludge; and

4. Define materials handling issues for test operations, such as a storage tank for sludge as it is pumped from the mock tank cell during testing.

Table 3.4. On-site off-the-shelf jet pump design tests

\begin{tabular}{ll}
\hline \multicolumn{1}{c}{ Test } & \multicolumn{1}{c}{ Objectives } \\
\hline $\begin{array}{l}\text { Operational testing with } \\
\text { variation in motive fluid } \\
\text { pressure }\end{array}$ & $\begin{array}{l}\text { Evaluate sludge flow rate and pump discharge pressure for varying } \\
\text { motive fluid pressures. Determine dead head pressure for each }\end{array}$ \\
$\begin{array}{l}\text { Line plugging maintenance } \\
\text { and debris }\end{array}$ & $\begin{array}{l}\text { Using simulated sludge and various debris forms, determine jet pump } \\
\text { plugging characteristics and verify techniques for unplugging the pump }\end{array}$ \\
Force/torque & $\begin{array}{l}\text { Determine forces and torques on MLDUA tool interface plate from mock } \\
\text { end-effector and mock HMS arm during siudge transfer operations. } \\
\text { Determine force/torque effect of sag in hose versus pulling on hose to } \\
\text { reduce sag }\end{array}$ \\
Performance curves & Develop performance curves for pressure versus capacity \\
HMS arm mechanics & Verify the mechanical aspects of the HMS arm design
\end{tabular}

\subsection{DEBRIS MANAGEMENT DESIGN TESTS}

Debris management tests shall be performed to characterize and define the techniques necessary to remove such debris from the tank floors. Debris management techniques will vary depending on the type of debris encountered in each tank. The types of debris anticipated to be encountered when performing waste removal operations in the gunite tanks include: fixed piping, pipe pieces, sampling equipment, personnel protective equipment, metal instrument tapes, pieces of chain, hand tools, level floats, and concrete pieces. The debris that is encountered and debris removal techniques that are developed will affect the mining strategy applied to removal actions within each tank.

Debris management techniques may include (without limitation): a raking method, a gripper arm and bucket method, or a vehicle used to push debris to within the reach of the manipulator arm. Debris removal techniques were demonstrated as part of an evaluation of vehicle systems for the Old Hydrofracture Tank program. A manipulator arm may be used for testing some of these techniques. The debris management techniques to be used have not been fully defined to date, so these test requirements will be developed further later.

Suggested tests for the development of debris management strategies and the objective of each test are listed below in Table 3.5. These tests will be performed on-site in the TTCTF. Specific test 
requirements and debris management equipment to be used will be defined further in the test plan. The information obtained during this testing will be used to verify the proper operation of the debris management equipment and techniques and to establish operating procedures to be used in the tank farm operations.

The debris management strategies developed for the tanks will greatly affect the mining strategies for cleaning the tanks. Much of the debris management and mining strategy issues will not be able to be addressed until performing operational testing in the NTF.

Table 3.5. Debris management design tests

\begin{tabular}{ll}
\hline \multicolumn{1}{c}{ Test } & \multicolumn{1}{c}{ Objectives } \\
\hline Debris pumping & $\begin{array}{l}\text { Determine the forces and torques applied to the manipulator arm when } \\
\text { pumping debris with jet pump and mock HMS; determine the types of } \\
\text { debris that can be pumped with the jet pumps without clogging or settling }\end{array}$ \\
Debris management & $\begin{array}{l}\text { Determine arm movements required and force/torque effects when using } \\
\text { the manipulator arm to manage debris }\end{array}$ \\
\hline
\end{tabular}

\subsection{CAMERA AND LIGHTING DESIGN TESTS}

This testing will be used to define the camera and lighting requirements to optimize the control room video display and the videorecords of the tank internals for the overview camera systems, two mast cameras and a gripper camera. Similar testing shall be performed for the cameras located in the containment structures of the MLDUA and WD\&C systems. Camera testing will be performed during operational testing of other equipment so that dynamic testing of the cameras under realistic conditions can be performed. The video cameras to be used during the TS operational testing program shall be tested at the TTCTF. The specific tests and the objective of each test are listed below in Table 3.6.

Table 3.6. Camera and lighting design tests

\begin{tabular}{ll}
\hline \multicolumn{1}{c}{ Test } & \multicolumn{1}{c}{ Objectives } \\
\hline $\begin{array}{l}\text { Field of vision } \\
\text { Focus }\end{array}$ & $\begin{array}{l}\text { Demonstrate ability to view all locations within the tank } \\
\text { Demonstrate manual and automatic camera focus requirements for effective } \\
\text { and repeatable focusing ability from a remote location }\end{array}$ \\
$\begin{array}{l}\text { Lighting } \\
\text { placement }\end{array}$ & $\begin{array}{l}\text { Define effective placement of lights for ability to view all locations within the } \\
\text { tank }\end{array}$ \\
Lighting design & $\begin{array}{l}\text { Define wattage requirements and quality of lighting needed for effective } \\
\text { illumination of tank internal area }\end{array}$ \\
$\begin{array}{l}\text { Viewing system } \\
\text { maintenance }\end{array}$ & $\begin{array}{l}\text { Demonstrate maintenance procedures for the viewing system. (The } \\
\text { maintenance is anticipated to occur outside of the tank) }\end{array}$ \\
\hline
\end{tabular}




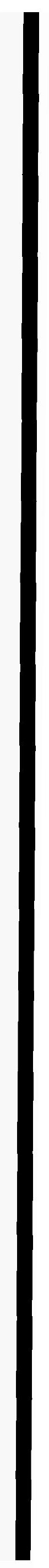




\section{ACCEPTANCE TESTS}

Acceptance tests will be performed at the equipment or instrument fabricator's facility to verify that the performance requirements of the equipment and instrumentation, as defined in the respective bid specification, are satisfied. Acceptance tests will be performed on:

- the decontamination spray ring, and

- the TRIC Box,

- the sludge transfer box,

- the WD\&C system, and

- the MLDUA.

The CSEE will be tested for acceptance following design testing to be performed at PNNL (Sect. 3.1.2). The jet pump may not be tested for acceptance, since the jet pump will be fabricated per its design specification. The machine shop selected for the jet pump fabrication may not be equipped for pump testing activities. Therefore, following delivery, the jet pump will be tested along with the WD\&C system.

\subsection{DECONTAMINATION SPRAY RING AND TRIC BOX ACCEPTANCE TESTS}

The decontamination spray ring and TRIC box shall be acceptance tested at Los Alamos Technical Associates, Inc. (LATA). The specific tests and the objective of each test are listed below in Table 4.1. These tests are to ensure that the spray rings and TRIC box are operational and to verify that the dimensions and containment requirements meet specification before shipment to ORNL.

Table 4.1. Decontamination spray ring and TRIC acceptance tests

\begin{tabular}{ll}
\hline \multicolumn{1}{c}{ Test } \\
\hline Containment box leakage & Verify that the containment box's seal meets design requirements \\
TRIC & $\begin{array}{l}\text { Verify that the TRIC interface seal with the decontamination spray ring } \\
\text { meets design requirements }\end{array}$ \\
Coverage & $\begin{array}{l}\text { Verify that the spray covers } 360^{\circ} \text { inside the ring } \\
\text { Vimensions }\end{array}$ \\
$\begin{array}{l}\text { End effector exchange } \\
\text { bechanism }\end{array}$ & Verify the proper operation of the end effector exchange mechanism \\
\hline
\end{tabular}

\subsection{WD\&C SYSTEM ACCEPTANCE TESTS}

The WD\&C shall be tested for acceptance at the fabricator's selected facility prior to shipment to ORNL. The acceptance testing is intended to confirm that the WD\&C is manufactured in strict 
accordance to the specifications and can perform the tasks required by the GAAT project. The tests include inspections and performance testing as detailed in Equipment Specification \#ES-GATT-001 for the Waste Dislodging and Conveyance System, of the Gunite and Associated Tanks - Treatability Study, prepared by Advanced Systems Technology, Inc. The specific tests and the objective of each test are listed below in Table 4.2.

Table 4.2. WD\&C acceptance tests

\begin{tabular}{ll}
\hline \multicolumn{1}{c}{ Test } & \multicolumn{1}{c}{ Objectives } \\
\hline Inspections & $\begin{array}{l}\text { Verify that the individual components (e.g., welds, etc.) of the WD\&C } \\
\text { meet design specifications }\end{array}$ \\
$\begin{array}{l}\text { Piping hydrostatic pressure } \\
\begin{array}{l}\text { Glove box and HMS } \\
\text { storage box pressure decay }\end{array}\end{array}$ & $\begin{array}{l}\text { Verify the piping assembly integrity with respect to leakage potential } \\
\begin{array}{l}\text { Form, fit, and } \\
\text { workmanship } \\
\text { demonstration }\end{array} \\
\begin{array}{l}\text { WD\&C system } \\
\text { functionality }\end{array}\end{array} \quad \begin{array}{l}\text { Verify the components of the system operate as required by the } \\
\text { specifications }\end{array}$ \\
\hline
\end{tabular}

\subsection{MLDUA ACCEPTANCE TESTS}

The MLDUA shall be tested off-site by Spar Aerospace Limited (SPAR). The specific tests and the objective of each test are listed below in Table 4.3. A detailed System Test Plan is provided in the Light Duty Utility Arm System DDR Data Package for ORNL MLDUA, Volume 1, prepared for Westinghouse Hanford Company, Richland, Washington, by SPAR.

The information obtained during this testing will be used to verify the proper operation of the equipment, as specified in the bid specification package. The acceptance testing is the first testing for the MLDUA associated with this program and will be completed after fabrication of the system and prior to shipment to ORNL. These tests will precede all on-site cold testing of the MLDUA. Written documentation of the test results shall be presented with the system. The test results will be reviewed and approved by Energy Systems prior to accepting delivery of the MLDUA system. All tests are to verify that the system meets the design objectives.

The design testing and subsequent acceptance testing for the first light duty utility arm (LDUA) were paid for by EM-50. 
Table 4.3. MLDUA acceptance tests

Test

Objectives

MLDUA subsystem

Functional checks of the various subsystems (e.g., hydraulic joints, camera, electrical components, etc.) In accordance with the System Test Plan, Light Duty Utility Arm and Deployment System (SPAR-LDUA-TP.023, Issue A) dated October 1995 (or subsequently issued versions of this test plan)

Payload

Verify design payload of arm

Control and range

Demonstrate and verify operational procedures and limitations

Verify operating ranges and limitations

Verify positioning accuracy

Verify correct operation of all controls and displays (software validation tests)

Determine local and remote operator control stations, and operate as required

Safety

Failure

Verify proper operation of the safety systems

Verify that the system operates per design upon loss of power. Verify that no transient motion occurs when power is restored

Demonstrate that the maximum loss of hydraulic fluid due to any failure does not release more than $5 \mathrm{gal}$

Collision

Verify through analysis that the collision of arm with unmovable structure will not damage arm, per design requirements

Performance

Verify the proper operation of various parameters in accordance with the specification's requirements including alignment, velocities, repeatability, etc. (See System Test Plan, LDUA and Deployment System (SPAR-LDUATP.023, Issue A) dated October 1995 (or subsequently issued versions of this test plan)

Endurance

Verify that the arm can operate for extended periods of time without failure

Maintenance

Verify that maintenance personnel can perform maintenance while wearing three pair of latex gloves in accordance with System Test Plan, LDUA and Deployment System (SPAR-LDUA-TP.023, Issue A) dated October 1995 (or subsequently issued versions of this test plan)

Reliability

Demonstrate that the arm can operate in the required environment

GISC interface

Verify that it can be operated using the GISC controls and can be switched between GISC and manual controls

Manual recovery

Demonstrate that the failed MLDUA can be recovered through a 23.5-in. riser as per MLDUA test plan (SPAR-LDUA-TP.023, Issue A) dated October 1995 (or subsequently issued versions of this test plan) 


\subsection{TRANSFER BOX ACCEPTANCE TESTS}

The transfer box shall be tested with water at the TTCTF. The transfer box will be fabricated, inspected, and tested as specified in the bid specification. If the manufacturer does not have the capabilities to perform this testing, it will be performed on site.

Specific transfer box tests and the objectives of each test are listed in Table 4.4. The test information obtained will be used to verify the transfer box meets the specified performance requirements. The specific requirements for the testing listed below are contained in the Equipment Specification for Gunite and Associated Tanks Treatability Study, Waste Slurry Transfer Piping and Instrumentation System, prepared by Jacobs Engineering Group.

Table 4.4. Transfer box acceptance tests

\begin{tabular}{ll}
\hline \multicolumn{1}{c}{ Test } \\
\hline Integrity & Verify that the transfer box was fabricated to the design specifications \\
Operations & Verify the components are operational as detailed in the specification \\
\hline
\end{tabular}




\section{$5-1$}

\section{FUNCTIONAL TESTS}

This section addresses functional testing to be performed at the ORNL TTCTF on the equipment and instrumentation as it arrives on-site. The TTCTF will be used to test the equipment in an environment to simulate a gunite tank, with an adjacent observation platform.

This testing will accomplish several critical goals:

1. Check equipment and instrumentation as it arrives on-site to ensure that no damage occurred during shipment.

2. Perform functional testing of equipment that was not reasonable to test at manufacturer's facility.

3. Establish "balance of plant" (BOP) interface requirements for current and future tests to be performed at the TTCTF. This includes establishing utility interfaces, materials handling systems, and procedures for sludge at the TTCTF.

4. Work out all "bugs," or system and test facility inadequacies, before the labor-intensive IS testing begins.

5. Provide the test team valuable "hands on" operational experience that will be beneficial in subsequent test phases.

6. Confirm that the safety features of the equipment are satisfied.

Functional testing will confirm the operability of the various components of the sludge transfer box and will test the appropriateness of operating and maintenance procedures of the various components and of the transfer box as an integral unit. The sludge transfer box includes control valves, a flow meter, and a proportional sampler. Functional testing of components such as the decontamination spray rings, and the transfer pipe manifold will be performed as part of the WD\&C system performance testing (Sect. 6.1).

\subsection{TRANSFER BOX FUNCTIONAL TESTS}

The functional testing of the sludge transfer box will be performed at the ORNL TTCTF when it arrives on-site. The transfer box components will be operated while simulated sludge is transferred through the transfer box. Specific transfer box tests and the objectives of each test are listed in Table 5.1. 
Table 5.1. Transfer box functional tests

\begin{tabular}{ll}
\hline \multicolumn{1}{c}{ Test } & \multicolumn{1}{c}{ Objective } \\
\hline Valve operations & $\begin{array}{l}\text { Verify the proper operation of the valves while simulated sludge is pumped } \\
\text { through the transfer box }\end{array}$ \\
Proportional sampler & $\begin{array}{l}\text { Verify the proper operation of the sampler while simulated sludge is pumped } \\
\text { through the transfer box }\end{array}$ \\
& $\begin{array}{l}\text { Demonstrate, revise, and finalize "hot" sampling procedures for collection of each } \\
\text { type of sample (i.e., sludge, slurry, water, etc.) }\end{array}$ \\
& $\begin{array}{l}\text { Ensure operator familiarity with sampling equipment operations and sample } \\
\text { collection/shipment protocols }\end{array}$ \\
Flow meter & $\begin{array}{l}\text { Demonstrate the following: } \\
\text { performance }\end{array}$ \\
& $\begin{array}{l}\text { Meter accuracy when measuring 1- and 2-phase flow (water and sludge) } \\
\text { - Indicator accuracy across loop from sensor } \\
\text { Meter repeatability when measuring 1- and 2-phase flow (water and sludge) }\end{array}$ \\
Decontamination & $\begin{array}{l}\text { Simulate flushing of the transfer box to demonstrate decontamination effectiveness } \\
\text { through flushing. Identify potential locations for sludge to accumulate. } \\
\text { Demonstrate each component's ability to drain. Identify low points that may } \\
\text { collect solids and/or water }\end{array}$ \\
Demonstrate "hot" maintenance of each component through access panels
\end{tabular}




\section{WASTE REMOVAL OPERATIONS IMPLEMENTATION}

This section addresses waste removal operations testing to be performed at the ORNL TTCTF. Waste removal operations to be tested include: WD\&C system performance, MLDUA performance, and IS performance. The WD\&C system and the MLDUA each will be operated and tested independently before being combined as an IS. If a robotic vehicle is added to the GAAT TS Operational Testing Program, then a vehicle test similar to the MLDUA test contained in Sect. 6.3 will be developed then.

During the waste removal operations at the TTCTF, mining strategies to be used in the NTF will be developed. A kinematic model of the tanks and existing hardware in the tanks will be developed using the modeling software package, IGRIP. This model will include the MLDUA, WD\&C system, overview camera system, tank structure, and platform structure located above the tanks. This model shall represent geometric shapes as well as ranges of motion for the various degrees of freedom in the subsystems. This model shall be used primarily to investigate positioning requirements to avoid interferences and collisions of obstacles or the WD\&C system with the MLDUA.

The model also will investigate the mining strategy for tanks waste retrieval operations. This mining strategy encompasses positioning and trajectory requirements for each of the various subsystems during deployment, end-effector grasping, sludge removal, tank wall and floor cleaning, decontamination, debris management, and stowing operations. The mining strategy investigations will initially address the TTCTF and NTF operations but will be expanded to address STF operations as well. To the extent that realistic models can be cost-effectively developed, the modeling effort will be expanded to include system dynamic behavior.

\subsection{WD\&C SYSTEM PERFORMANCE TESTS}

The WD\&C system includes the jet pump, HMS, CSEE, WD\&C containment box and associated drive systems, decontamination spray ring, and TRIC component. The WD\&C system performance testing also will incorporate testing of the BOP system components. In these performance tests, the WD\&C and BOP components shall be operated as a complete waste removal system, without the use of the MLDUA for positioning.

The performance testing of the WD\&C system will build on the testing of individual components performed earlier. Specific performance tests and the objectives of each test are listed in Table 6.1. The data obtained during this testing will be used to estimate resource (labor, utility, and cost) requirements and personnel exposures for future tank farm operations.

This performance testing will accomplish several critical goals before personnel enter a "hot" environment:

1. Establish desired operating envelopes for equipment;

2. Provide training of operations personnel;

3. Allow testing, revision and finalization of operating procedures;

4. Allow testing, revision and finalization of maintenance procedures;

5. Allow testing, revision, and finalization of installation and equipment transport procedures; 
6. Provide documentation for readiness assessment review of the operating system and operations personnel;

7. Provide information to estimate exposures for activities in tank farm operations; and

8. Provide information to support implementing "as low as reasonably achievable" (ALARA) philosophy in operations and to confirm safety procedures and requirements.

The tests will be conducted using simulated sludge with a varying range of consistencies. This performance testing of the WD\&C system will demonstrate the following:

- WD\&C System Management (Transportation, Installation and Removal): The equipment should be transported, installed and removed by the same personnel who will be performing these activities in the tank farm operations so that performance of these activities can also serve to train the personnel.

- System Start-up/Shutdown: WD\&C start-up and shutdown activities may be performed as part of standard WD\&C operating activities. Performance of startup/shutdown activities will be used to verify operating procedures and to estimate labor requirements and personnel exposures for implementing tank farm operations.

- Normal Operation: Test results from normal operations and off-normal events shall be used to verify the proper operation of the equipment and to verify the accuracy of and refine the operating procedures required for the system. The CSEE will be available for testing as a WD\&C system inlet to the jet pump. However, without the MLDUA available to control the CSEE during sluicing, extensive testing of the sluicing technology may not be possible until performance testing of the IS is performed.

- WD\&CMaintenance: Demonstration of recovery from equipment, instrument, and system failures shall be performed through the glove box with appropriate hand protection (gloves) to simulate a hot test environment. The test plan for this activity shall address how to simulate each failure and the maintenance actions for each failure.

- Instrumentation: The sampling system, flow meter, decontamination spray ring, TRIC, and transfer/valving box shall all be tested for demonstration of operability and maintenance issues. These components will be tested during the testing activities described in Sect. 6, Waste Removal Operations Implementation.

Table 6.1 lists the specific tests and the objectives of each WD\&C system performance test.

Table 6.1. WD\&C system performance tests

Test

Hoisting and rigging

\section{Objectives}

Demonstrate and verify hoisting and rigging equipment operations and procedures

Demonstrate any special tools required for hoisting and rigging and validate their operability

Document time required to perform hoisting and rigging operations for estimation of cost and exposure durations to be encountered in tank farm operations 
Table 6.1 (continued)

Test

System assembly

System disassembly

System deployment/ retraction

Start-up/shutdown

Decontamination

HMS kinematics
Demonstrate and verify equipment operations and procedures

Demonstrate any special tools required for system assembly and validate their operability

Document time required to perform system assembly operations for estimation of cost and exposure durations to be encountered in tank farm operations

Demonstrate and verify equipment operations and procedures

Demonstrate any special tools required for system disassembly and validate their operability

Document time required to perform system disassembly operations

Demonstrate and verify the deployment/ retraction operations and procedures

Demonstrate and verify the following:

- Equipment operation and procedures for deployment

- Equipment operation and procedures for retraction

Determine the control coordination requirements during start-up and shutdown operations for BOP equipment (start/stop high pressure pumps, etc.)

Record operation times and other parameters that could be used to determine waste-removal operation costs

Demonstrate the function and effectiveness of the WD\&C decontamination process

Record water requirements, time requirements and number of passes to effectively clean the equipment per decontamination event and for demobilization event

Document waste storage capacity required

Determine the following:

- Effects of air in suction line on pumping sludge

- Effects of air in horizontal line following jet pump on pumping sludge

- Potential for sludge deposition in transfer lines for various sludge

Demonstrate sludge transfer through the full range of motion for the HMS in both the passive and active modes 
Table 6.1 (continued)

Test Objectives

Operations

Failure recovery

Pump change-out

Line plugging maintenance

Line flush

Maintenance at mock laydown area

Instrument and valve maintenance

Decontamination spray ring functional

Transfer/valving box leak

Transfer/valving box decontamination

Transfer/valving box controls
Verify the system's independent controls

Verify desired operating envelope for jet pump using varying sludges

Determine the following:

- Height and depth of pumping-action cone of influence

- Amount and percent of solids removed per operating time

- Rate of motive fluid required

- Rate of slurry discharged

- Control coordination requirements for BOP equipment integration into the system

Document equipment and instrument failures and mean time between failures

Evaluate the effectiveness of line flushing

Demonstrate system reaction as defined in design specifications and recovery from failures which may include the following:

- $\quad$ Power loss to total system

- Power loss to individual critical components

- Emergency stop

- Instrumentation/control loss

- High pressure hydraulic line rupture

- Conveyance line rupture

- Swivel joint failure

- Cable failure

- Camera failure

- $\quad$ Plug in the line

Determine pump change-out time and verify change-out procedures

Determine jet pump plugging characteristics (with high density sludge and with debris) and verify procedures for unplugging the pump and transfer lines

Evaluate the effectiveness of line flushing after a failure or normal shutdown event

Simulate:

- $\quad$ system transport to maintenance area

- maintenance actions in mock lay down area

Demonstrate the ability to perform maintenance on all instrumentation and valves

Verify that the decon spray covers $360^{\circ}$ of WD\&C system

Verify sludge removal effectiveness

Leak test the transfer/valving box connections on all sides

Demonstrate the ability of the transfer box to be flushed of solids using WD\&C backflush valve lineup

Demonstrate the ability to perform control functions 


\subsection{MLDUA PERFORMANCE TESTS}

Before delivery to ORNL, the MLDUA will have undergone extensive acceptance testing criteria, as outlined in Sect. 4 of this document and as detailed in the Light Duty Utility Arm System DDR Data Package for ORNL MLDUA, Volume 1, prepared for Westinghouse Hanford Company, Richland, Washington, by SPAR. The testing performed at the TTCTF will not repeat these acceptance tests. Also SPAR will provide written procedures for transportation, installation, operation, and maintenance of this equipment. These documents will be used as a baseline for the following testing, and will be modified as required.

The MLDUA performance tests shall demonstrate:

- MLDUA transport and installation: The MLDUA transport tests will demonstrate the maneuverability of the MLDUA equipment; hoisting and rigging requirements to position the system in the tanks and will demonstrate the transportation and installation procedures. These tests will be performed on-site as part of the actual transport and installation of equipment to the TTCTF.

- MLDUA operation and control: The MLDUA operations performance tests will establish the boundary conditions for the operation of the MLDUA within a simulated tank environment. The MLDUA control systems performance tests will verify the accuracy and dependability of the control systems. Any controls that cannot be tested at this time will be tested during the IS testing. The tests will be completed without the system being interfaced with the WD\&C system. These tests will verify procedures that will be used during actual remediation activities and will provide valuable training for operations personnel. The procedures are intended to verify the proper operation of the control systems and to provide repeatable and safe practices for operation and failure detection of the system.

- Camera operation and control: The camera performance tests will verify and demonstrate the integrated operation of the cameras and illumination equipment with the MLDUA.

- Tool-End Effector operation: The MLDUA tool end-effector performance tests will be used to verify the proper operation of the MLDUA with all end-effector attachments that will be used during the tank farm operations. These tests will also be used to demonstrate, revise as needed, and finalize written procedures for operations.

- MLDUA maintenance: These tests will also be used to demonstrate, revise as needed, and finalize written procedures for MLDUA maintenance operations.

During this testing, the kinematic model of the tanks and existing hardware in the tanks will be further refined. Testing of the MLDUA will also serve as training of personnel in preparation for tank farm operations. The specific tests to be performed and the objectives of each test are listed in Table 6.2. 
Table 6.2. IS performance tests

Tests

Hoisting and rigging

Tank deployment

Manual retraction

System decontamination and transport

Operational controls

Manual controls

Data display equipment
Demonstrate and verify hoisting and rigging equipment and procedures

Demonstrate any special tools required for hoisting and rigging and validate their operability

Document time required to perform hoisting and rigging operations for estimation of cost and exposure durations to be encountered in tank farm operations

Perform mock scenarios to prepare operators for each condition (training)

Demonstrate, revise, and finalize written procedures for positioning and deployment of the MLDUA

Demonstrate any special tools required for tank deployment and validate their operability

Perform mock deployment scenarios (training)

Demonstrate, revise and finalize written procedures for manual retraction of the MLDUA during "non-powered" operations

Demonstrate any special tools required for manual retraction of the MLDUA and validate their operability

Perform mock retraction scenarios for all potential situations (training)

Demonstrate, revise, and finalize written procedures for decontamination and transport of the MIDUA

Perform mock decontamination and transport scenarios (training)

Document time required for decontamination and volume of water used

Demonstrate, revise, and finalize written procedures for operation of the MLDUA

Verify that the MLDUA can be operated, as needed, in a failed mode using manual controls

Demonstrate, revise, and finalize written procedures for operation in this mode

Verify that all of the data display equipment is in place and operational

Establish monitoring, logging and maintenance requirements for each piece of equipment

Perform mock maintenance scenarios for maintenance procedures (training)

Determine the following with respect to the MLDUA:

- Ability to reach all areas of the floors and walls

- Maneuverability of the MLDUA around obstacles in the tanks

- Ability to move and hold specified payloads in required directions 
Table 6.2 (continued)

Tests

Camera operations

Camera

maintenance

End effector deployment and change

Tool end-effector calibration

End-effector operations

MLDUA maintenance

Failure recovery

Document equipment failures
Objectives

Verify that the camera and lighting system operate properly after installation on the MLDUA. Information obtained shall include:

- Field of vision

- Focus

- Lighting design and placement

- Lens cleaning

Demonstrate and revise written maintenance procedures (to include lens cleaning) for the camera and lighting systems

Demonstrate and revise procedures for changing end effectors to safely accomplish these activities with ALARA exposures

Demonstrate and revise procedures and calibrate the equipment after deployment of end-effector

Demonstrate and revise procedures and verify operations of each end-effector with the MLDUA

Perform routine maintenance and demonstrate and revise written procedures for maintenance of the systems included in the MLDUA (electronic, pneumatic, hydraulic and mechanical)

Perform mock maintenance scenarios for the maintenance procedures (training). For example: end effector change out and MLDUA connector line purge

Document time required to demonstrate maintenance actions to estimate cost and exposures for tank farm operations

Demonstrate, verify as defined in the specifications, revise and finalize procedures for recovery from failures for each MLDUA system arrangement. These failures may include the following:

- Power loss

- E-kill

- Instrumentation/control loss

- Hydraulic line ruptare

- Pneumatic line rupture

- Mechanical breakage

- Camera failure

- "Boot" failure

- Control system failure

Testing and checkout may identify additional failure scenarios

During operations and maintenance activities conducted in performance testing, each unplanned failure event and associated downtime shall be monitored and logged 


\subsection{IS PERFORMANCE TESTS}

This test program was developed under the assumption that the MLDUA will be integrated with the WD\&C system for NTF operations. A robotic vehicle may be used to navigate the WD\&C system, or to push material to the WD\&C system inlet. If a robotic vehicle is used, then this IS test section will be modified to test the vehicle and the WD\&C system together, and the MLDUA will be tested separately. This section of the test program will be modified at that time.

For the current scenario, at the time that the MLDUA grasps the CSEE of the WD\&C system, the subsystems (MLDUA, WD\&C, and BOP) become the IS. The IS performance tests shall include demonstration, revision, and finalization of procedures for the activities to be performed in the tank farm operations. The IS performance tests will be used to verify the proper operation of the IS and to provide full system training of the operators and training verification before tank farm operations. During the operation of the IS, the number of workers required for tank farm operations will be evaluated, and the time spent in a potential radiological area will be evaluated for ALARA review, if necessary.

Total times (and associated costs where available) for equipment transportation (between risers and tanks), deployment, system checkout, maintenance activities, sample collection, start-up, shut-down, and system demobilization should be monitored and logged for all IS tests. Instrument and equipment failures that occur during the IS performance tests will be used to validate vendor-recommended spare parts lists.

Mining strategies developed during previous testing will be demonstrated and refined for surrogate sludge of varying compositions and shall be tested using the IS. Debris removal techniques shall also be tested as these procedures are considered part of the overall mining strategy.

The information obtained during this testing will be used to refine the mining strategy procedures to be used in the NTF Operations, which in turn will be used to refine the mining strategy procedures to be proposed for use in the STF. The simplicity or complexity of the mining strategies developed will depend on the various ranges of motions possible with the IS and on the varying physical and chemical characteristics of sludge anticipated to be encountered in tank farm operations. The mining strategies to be developed depend on several factors, including:

- tank construction,

- equipment configuration,

- tank sludge chemical and physical characteristics, and

- tank cleaning goals.

Operating parameters that can be varied to optimize mining strategies include (without limitation):

- jet pump motive fluid flow rate,

- CSEE linear speed,

- cutting jet water pressure,

- CSEE stand-off distance,

- the positioning of the WD\&C HMS and of the MLDUA, and

- the tracking speed and equipment staging requirements of moving all the systems as an integrated unit. 
Any maintenance or other work that is performed should be evaluated while in appropriate personal protective equipment (PPE) for the anticipated future hot work scenario and following ORNL radiological protection procedures to the extent practical.

Operator training for failure response of the different component systems of the IS will have been accomplished during the component system WD\&C and MLDUA performance tests. However, unique situations may arise during the IS operations testing that will require further operator and maintenance personnel training. This training will be achieved during the integrated performance tests listed in Table 6.3.

Table 6.3. IS performance tests

\begin{tabular}{|c|c|}
\hline Test & Objectives \\
\hline \multirow[t]{2}{*}{$\begin{array}{l}\text { System installation and } \\
\text { integration }\end{array}$} & $\begin{array}{l}\text { Verify procedures for installation and integration of the MLDUA and WD\&C } \\
\text { systems }\end{array}$ \\
\hline & $\begin{array}{l}\text { Record operation times and other parameters for installation and deployment of } \\
\text { equipment }\end{array}$ \\
\hline \multirow{2}{*}{$\begin{array}{l}\text { IS demobilization and } \\
\text { transport }\end{array}$} & Demonstrate procedures for demobilization and transportation of the IS \\
\hline & Practice each operation as necessary \\
\hline Debris management & $\begin{array}{l}\text { Demonstrate arm movements required and force/torque effects when using } \\
\text { MLDUA to manage debris. Demonstrate method to wash debris }\end{array}$ \\
\hline \multirow[t]{3}{*}{$\begin{array}{l}\text { Performance of sludge } \\
\text { removal }\end{array}$} & $\begin{array}{l}\text { Verify IS range of motion and perform checkout of the IS with both passive HMS } \\
\text { and an interactive joint driven HMS to verify which mode of operation is } \\
\text { preferred }\end{array}$ \\
\hline & $\begin{array}{l}\text { Confirm solids removal efficiencies for selected mining strategies using surrogate } \\
\text { sludge of varying densities. Parameters to be monitored during sludge transfer } \\
\text { and scarifying operations, and boundary conditions verified, during the } \\
\text { performance testing include: } \\
\text { - jet pump motive fluid pressure } \\
\text { - cutting jet water pressure } \\
\text { - } \quad \text { CSEE stand-off distance } \\
\text { CSEE linear speed }\end{array}$ \\
\hline & $\begin{array}{l}\text { Monitor and record the CSEE, jet pump, and HMS operating force/torques on the } \\
\text { MLDUA during: } \\
\text { - } \quad \text { sluicing operations } \\
-\quad \text { scarifying operations } \\
-\quad \text { multi-phase pumping due to air effects (dynamic and static loads) }\end{array}$ \\
\hline
\end{tabular}


Monitor and record the effects on the MLDUA when the CSEE is dragged across the tank floor

Demonstrate equipment tracking scenarios using developed mining strategies for full tank coverage

Document residual sludge left in tank following each mining strategy test

Document approximate solids concentration throughout mining activities:

- per unit operating time

- $\quad$ per unit water added at jet pump

- per unit water added at CSEE

- per unit water added at CSEE

- per unit water added at CSEE

Demonstrate removal techniques for debris that is capable of being pumped and document efficiencies. Record force/torque data from these operations

Demonstrate HMS arm movement capabilities after the arm is positioned inclined off-normal to the tank floor surface

Verify solids removal efficiencies using developed mining strategies fr surrogate sledges at varying densities

Other parameters to be monitored and documented during this testing include:

- supernate removal rate

- number of operators required for IS operation

- BOP coordination requirements

- human factors upon operator duty cycle

- $\quad P P E$ and other disposable equipment used during mining activities

- equipment duty cycles

- mean time between equipment failures

- time spent working on potential "hot" equipment

Decontamination

Failure recovery

Performance of gunite cleaning/removal

Maintenance
Demonstrate decontamination ring effectiveness. Document volume of water used in decontamination ring and spray wand decontamination events, and number of decontamination events

Document system reaction to and recovery from failures which may include:

- Cutting jet plug

- Cutting jet fracture

- Loss of hydraulic pressure

- Conveyance line rupture

- Swivel joint failure

- Camera failure

- Cable failure

- Failure caused by any unique situations resulting from equipment interface such as failure of gripper end effector

- Failures that occur during normal operations

Determine gunite cleaning/scarifying efficiencies using established cleaning/scarifying pressures

Perform mock, or real, maintenance actions through glove box. Include demonstration of "bag-in/bag-out" procedures. Document time required for maintenance activities during mining strategy performance test 


\section{NTF OPERATIONS}

The GAAT TS operations testing in a "hot" environment will be performed on two gunite tanks (W-3 and W-4) in the GAAT NTF. These tanks were selected for the TS because their lower contaminant inventory presents less risk to workers and the environment for the first field deployment of the developmental waste removal systems. The NTF operations will be used to verify that all operating procedures and ORNL radiological protection procedures are sufficient for the protection of all workers and the environment before proceeding to the GAAT STF, which is categorized as a Category 3 nuclear facility.

The IS will be installed in the NTF in the configuration that will be used for the tank farm operations. Total times (and other parameters that can be used to determine costs where available) for system transportation (between risers and tanks), deployment, system checkout, maintenance activities, sample collection, start-up, shut-down, and system removal should be monitored and logged for all NTF operations. Logs will also be maintained to monitor personnel exposure for each activity, the amount of PPE used for each activity, the rate of equipment failure, and the amount of clean water used. When applicable, maintenance procedures will be performed using "pinky rings" to monitor additional exposure to hands when applicable.

Mining strategies that have been developed during the performance testing will be refined for actual NTF sludge compositions. The mining strategies to be developed depend on several factors, including: the cone of influence of the CSEE, the range of motion of the WD\&C HMS and of the MLDUA, the tracking speed and equipment tracking requirements of moving all the systems as an integrated unit, and the linear speed of the CSEE, among other parameters.

These operations will accomplish several critical goals before entering the STF. They are as follows:

- verify sufficiency of procedures;

- refine mining strategy;

- collect cost and timing data that will be used to estimate remediation costs; and

- collect various other information to include PPE usage, personnel exposure times, equipment maintenance requirements, etc.

Table 7.1 further details the individual tests and their objectives which will be performed in the NTF operations.

Table 7.1. NTF operations

\begin{tabular}{ll}
\hline \multicolumn{1}{c}{ Test } & \multicolumn{1}{c}{ Objectives } \\
\hline $\begin{array}{l}\text { System installation and } \\
\text { deployment }\end{array}$ & $\begin{array}{l}\text { Confirm procedures for installation of the IS } \\
\text { Record operation times and other parameters for installation and deployment } \\
\text { of equipment }\end{array}$
\end{tabular}


Table 7.1 (continued)

Test

System checkout

Debris management

Waste removal operations

motion

Demonstrate equipment tracking scenarios using developed mining strategies

Demonstrate sampling procedures

Document human factors affect upon operator duty cycle

Determine solids removal efficiencies using developed mining strategies

Some parameters to be monitored during the operations include:

- jet pump motive fluid pressure

- $\quad$ cutting jet water pressure

- Operating force/torques

- $\quad$ CSEE Linear speed

Document solids concentration throughout mining activities:

- per unit operating time

- $\quad$ per unit water added at jet pump

- per unit water added at CSEE

Demonstrate removal techniques for pumpable debris and document efficiencies (if encountered), and document force/torques at MLDUA during pumping

Confirm debris management procedures

Demonstrate supernate removal techniques and document efficiencies

Other parameters to be monitored and documented during NTF operations include:

- $\quad$ PPE and other disposable equipment used during mining activities

- $\quad$ equipment duty cycles

- mean time between equipment failures

- time spent working on "hot" equipment

Document all system failures and response times/exposures during the NTF testing

Performance of gunite removal
Determine gunite scarifying efficiencies using established scarifying pressures 
Table 7.1 (continued)

Test

Maintenance Test

IS Demobilization and Transport Test
Objectives

Confirm required procedures for routine and emergency maintenance, and equipment decontamination activities associated with the IS

Document volume of water used in decontamination events, and number of decontamination events

It will also be necessary to document the following with respect to radiation exposures:

- $\quad$ Time required to complete maintenance

- $\quad$ Actual exposures (dose rates) for maintenance activities

- Equipment contamination level after use in hot environment and decontamination procedures

If maintenance activities are not required during NTF operations, simulate maintenance activities at the completion of the NTF operations to inspect decontamination effectiveness and to perform routine maintenance check

Confirm procedures for demobilization of the IS after exposure to a hot environment

Document volume of water used in decontamination events, and number of decontamination events

Document effectiveness of decontamination spray ring using methods such as visual criteria and radiation readings before and after decontamination (method to be refined in development of test plan)

Other factors which may either be required for successful completion of the TS or helpful for completion of the selected remedy are listed below:

- Other waste characteristics that would cause processing or exposure problems;

- Quantity of waste that will be disposed;

- Organic compound concentration of the resultant wastes;

- Metals concentrations in resultant wastes;

- Quantities of secondary wastes generated per day;

- Operational interfaces (volumes, solids content, schedules, etc.) for sludge transfer;

- Tributylphosphate skimmer selection and use prior to TS in NTF;

- Remediation completion criteria;

- Human health risk of tank contents;

- Platform information; and

- Quantity of transuranic waste remaining after remediation completion.

Some of the above information can be determined by collecting and analyzing samples during the 
operational testing program, and evaluating resulting data. More detailed information on the subjects listed above and other items that must be considered parallel to the testing activities are included in Appendix A.

Other information is necessary for the evaluation of remedial alternatives for the FS, but does not directly require data to be collected in the TS. This information is presented in Appendix B and contains the following:

- Health and safety plans, conduct of operations assessment summary report, waste management plans, etc.;

- Cleanliness criteria;

- $\quad$ STF waste characteristics;

- Melton Valley Storage Tanks acceptance criteria;

- Final waste state (for both NTF and STF);

- Other waste treatment technologies (i.e., vitrification, stabilization, etc.);

- Human health risk information from STF tanks, etc.;

- Exposure estimates for the STF;

- Estimate the life cycle of each of the components of the MLDUA using failure information gathered during testing or manufacturer recommendations and determine preventive maintenance requirements;

- Safety documentation; and

- Permits and approvals.

The information collected during the operational testing program will be combined with other reports and actions to meet overall objectives of TS. 


\section{DEVELOPMENT OF TEST PLANS}

Test plans and procedures will be developed for each of the tests listed in Sects. 3 through 7 of this plan. The test plans and procedures will establish the needed formality of operations for testing, testing objectives, specific test results required (qualitative and quantitative), test criteria, DQOs, health and safety requirements, schedules and costs.

In generating the test plans, the data requirements listed in Appendix A should be referenced to ensure that all required data are collected. This will also focus the test plan so that unnecessary data will not be collected.

These plans and procedures should be formatted as follows (a description of what is contained in each section is included):

1. PURPOSE: Include the purpose of the testing to be performed.

2. SCOPE AND LIMITATIONS: List the scope of each specific test and any associated limitations.

3. DEFINITIONS: Include definitions for any unusual words or specific procedures that will be included in the test plan.

4. MATERIALS AND EQUIPMENT NEEDED: List all materials and equipment that are needed to complete the testing activities.

5. RESPONSIBILITIES: List the titles for individuals that are participating in the testing activities. Define the titles and list who (or what organization) is responsible for supplying the personnel to perform in the defined role. Also list the responsibilities of each project title.

6. INITIAL CONDITIONS FOR TEST: Establish all initial test conditions including safety, as well as any other conditions that must be met prior to beginning the testing.

7. TEST SEQUENCE: List the sequence of testing activities.

8. DATA COLLECTION REQUIREMENTS: List of all data that must be collected during the test.

9. STANDARDS/ REFERENCES: List all buyer and industry recognized documents, standards and references that are necessary for the tests.

10. RECORDS RETENTION: List the records retention policies for the testing.

11. APPENDICES/CHECKLISTS/LOG SHEETS: Include any other information that is pertinent to the test plan execution.

The test plans will contain a table of system parameters that have been developed for each test to establish a performance baseline prior to operation in the NTF. Also, the test plan for the operations in the NTF will address preliminary operations to establish baselines and data accuracy prior to waste heel removal testing.

A sampling and analysis plan may also be required for NTF operations. The sampling and analysis plans will be prepared using existing plans that have been developed for the GAAT project. 



\section{TEST PLAN DEVIATIONS}

Throughout the duration of the GAAT TS Operational Testing Program, deviations to the program's technical, schedule, and cost baselines are likely to occur. Specifically, program changes may occur due to technical challenges, design delays, procurement delays, equipment failures, etc. Procedures are required to address the impacts of each change on the program's scope, cost, and schedule. These procedures are included in the GAAT TS Configuration Management Plan. This plan will be the governing document used to control all project changes. 



\section{DATA MANAGEMENT AND QUALITY CONTROL}

GAAT TS Operational Testing Program data items include the following:

- Draft and final test plan documents

- Draft and final test procedures documents

- Draft and final test reports

- Project status reports

- Draft and final conference notes for readiness reviews, monthly meetings, etc.

Other types of program data include raw and reduced test data. All test data shall be recorded, reduced, analyzed, and reported in accordance with the program's test plans, test procedures, approved test report format, DQO process, and QA Plan. Relevant test data will typically be included in the appendices of the test reports. QC requirements and procedures for collection and analysis of the data will be in accordance with the DQO process and QA Plan and should be detailed in each test plan. 


\section{SCHEDULE}

The testing activities conducted in accordance with this operational testing program will be conducted in accordance with the schedule included in Appendix C. This schedule is intended to be a living document and should be updated as required to accurately track ongoing operation testing activities. 



\section{TEST LABOR RESOURCES}

Multidisciplined labor resources will be required for all phases of GAAT operational testing activities. The phases of each test activity shall include, but are not limited to:

- test planning,

- test procedure writing,

- equipment procurement,

- test-rig equipment procurement,

- test equipment assembly and set-up,

- test operation,

- test data analysis and reduction,

- test report writing,

- test equipment tear-down and disposal, and

- miscellaneous materials disposal.

Various test discipline personnel shall include but are not limited to:

- purchasing personnel,

- test technicians,

- construction trade labor personnel,

- engineers,

- health physicists,

- shielding personnel,

- safety personnel,

- reviewers,

- project managers,

- project controls personnel,

- quality assurance personnel,

- document control personnel,

- environmental compliance personnel, and

- report writers.

The types and level of support required for specific tests will be developed with the detailed test plan. 



\section{REFERENCES}

DDR Data Package for ORNL MLDUA, Volume I, Description and Analysis (SPAR-LDUADR.054), prepared by Spar Aerospace Limited.

DOE. (U.S. Department of Energy). 1992. Federal Facility Agreement for the Oak Ridge Reservation, DOE/OR-1014. U.S. Department of Energy, Oak Ridge, TN.

DOE. 1995. Gunite and Associated Tanks Operable Unit Baseline Report and Treatability Study Work Plan, Oak Ridge, Tennessee, DOE/OR/02-1325\&D2. Department of Energy, Oak Ridge, TN.

Energy Systems. (Lockheed Martin Energy Systems, Inc.) 1995. Results of 1995 Characterization of Gunite and Associated Tanks at the Oak Ridge National Laboratory, Oak Ridge, Tennessee, Draft, ORNL/ER/Sub/87-99053/79. Oak Ridge, TN.

Energy Systems. 1996. Equipment Specification for Gunite and Associated Tanks Treatability Study Waste Transfer System Piping and Instrumentation System.

Energy Systems. 1996. Equipment Specification \# ES-GATT-001 for the Waste Dislodging \& Conveyance System of the Gunite and Associated Tanks - Treatability Study

EPA. 1992. Guide for Conducting Treatability Studies under CERCLA, Final, EPALS40IR921071a. Office of Solid Waste and Emergency Response, Washington, D.C. 


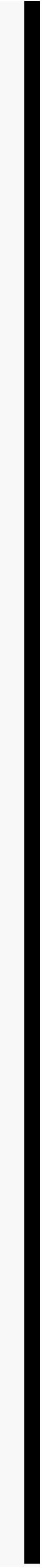




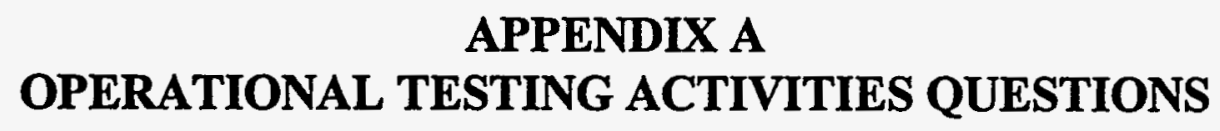



JET PUMP DESIGN TESTS

Jet Pump Design Test

1. How much water needs to be added per unit of waste removed?

\section{DATA REQUIREMENTS}

Volume of motive water.

Volume of cutting jet water.

Volume of slumy discharged.

Verified in Hot test.

2. What is the cone of influence of pumping action in simulated sludge?

Height and depth of cone of influence

1. In sludge w/ s.g. of 1.9

2. In several different sludge consistencies

3. How much water will be added per unit of sludge removed?

4. What are the affects of the transition between pumping air and pumping water? Measure path

force/torque sensor.

1. Test in simulated sludge w/sluicing

2. Test in simulated sludge w/out sluicing

3. Test with debris

5. What is minimum suction lift delivered by Jet Pump using various surrogate sludges?

1. $\ln 11 / 2$ "line

2. $\ln 2^{\prime \prime}$ line

6. Can we use lower pressure water to the jet pump?

1. What pressure will optimize the rate of cleaning?

7. Can the jet pump remove debris?

1. Various sizes of debris

8. What is pressure in disharge line?

9. What are line unplugging/unclogging procedures?

10. What is plugging potential for various forms of debris?

Gallons of water added during sludge removal

operations

Induce multi-phase flow and measure w

Change in flow rate.

Change in solids transfer

Determine TDH required for simulated sludge,

verify in Hot Test.

1

Determine pressures required for pumping sludge.

Determine what plugs the jet pumps, if anything.

Measure the discharge pressure in line at several operating conditions

IDevelop procedures for unclogging-unplugging line

Test jet pump debris handling ability w/out CSEE operation 


\section{CSEE DESIGN TESTS}

CSEE Design Tests

1. What are optimal CSEE set-up parameters for corner cleaning?

1. nozzle angle?

2. pressures?

3. flow rates?

2. What are the optimal CSEE set-up parameters for tank floor cleaning?

1. nozzle angle?

DATA REQUIREMENTS

2. nozzle size?

3. pressures and flow rates?

Measure cleaning efficiency and effectiveness

at varying angles

Measure percent solids in effluent

Measure cleaning efficiency and effectiveness

at varying angles

Measure percent solids in effluent

Measure cleaning efficiency and effectiveness

at varying angles

Measure percent solids in effluent

Various pre-manufactured models to be tested.

Measure cleaning $\epsilon$.ficiency and effectiveness

at varying angles

Measure percent solids in effluent

Measure cleaning efficiency and effectiveness

at varying nozzle sizes

Measure percent solids in effuent

at varying pressures

Measure percent solids in effluent

3. What pressure will optimize the rate of cleaning?

4. How much water will be added per unit of sludge removed?

5. What are the optimal CSEE set-up parameters for tank wall cleaning/scarifying? 1. nozzle angle?

Optimum operating pressure

Gallons of water added during sludge removal

operations

\section{2. nozzle size?}

Measure cleaning efficiency and effectiveness

at varying angles

Measure percent solids in effluent

Measure cleaning efficiency and effectiveness

at varying nozzle sizes

Measure percent solids in effluent

3. pressures and flow rates?

Measure cleaning efficiency and effectiveness

at varying pressures

Measure percent solids in effluent

6. What tolerance is acceptable for CSEE stand-off distance?

Test efficiency and effectiveness of CSEE

1. In water?

2. In surrogate sludge?

7. What pressures are required to scabble the wall?

at varying distances: use SCEE w/o stand-off control

1. Will tank walls withstand scabble action?

Test scabble efficiency and effectiveness

at varying pressures and distances and on varying materials 

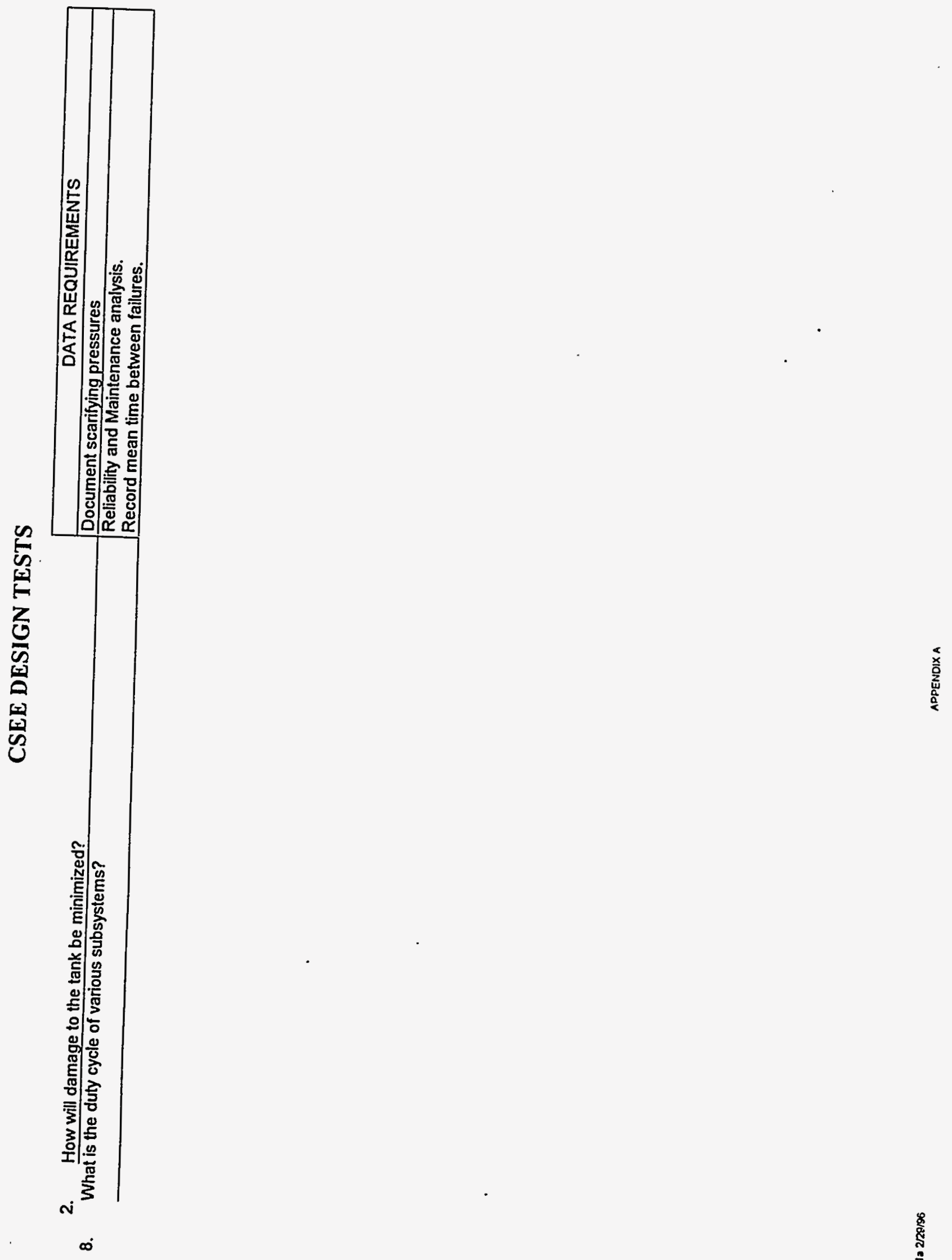


\section{CAMERA \& LIGHTING DESIGN TESTS}

Camera \& Lighting Design Tests

.

1. Modified Light Duty Utility Arm (MLDUA) Questions

1. What are the best viewing properties for mining operations?

1. Field of Vision

2. Zoom

3. Lighting

4. Lens Cleaning

5. Refractive Index

6. Focus

7. Affect of Supernate

Vary camera position, lighting and camera features Vary camera position, lighting and camera features

Vary camera position, lighting and camera features

Vary camera position, lighting and camera features Vary camera features

Vary camera features

Vary camera position, lighting, and camera features 


\section{DEBRIS MANAGEMENT DESIGN TESTS}

Debris Management Design Tests

1. How will debris be handled?

DATA REQUIREMENTS

2. What is loading on MLDUA when pumping debris?

Characterize types of debris to be encountered

3. How will large debris be removed from tanks?

Utilize Schilling arm and Mock HMS with

pumping debris and logging forceltorque data

Utilize Schilling arm to test debris removal

techniques 


\section{DECONTAMINATION SPRAY RING AND TRIC ACCEPTANCE TESTS}

Decon Spray Ring \& TRIC Acceptance Tests

1. Does spray ring have correct coverage for decon-ability?

2. For MLDUA spray ring - check TRIC interface for leaks

3. Verify dimensions of mechanical interface to other systems

4. Check spray piping connections for leaks

5. Check spray ring and bellows interface for leaks DATA REQUIREMENTS 


\section{MLDUA ACCEPTANCE TESTS}

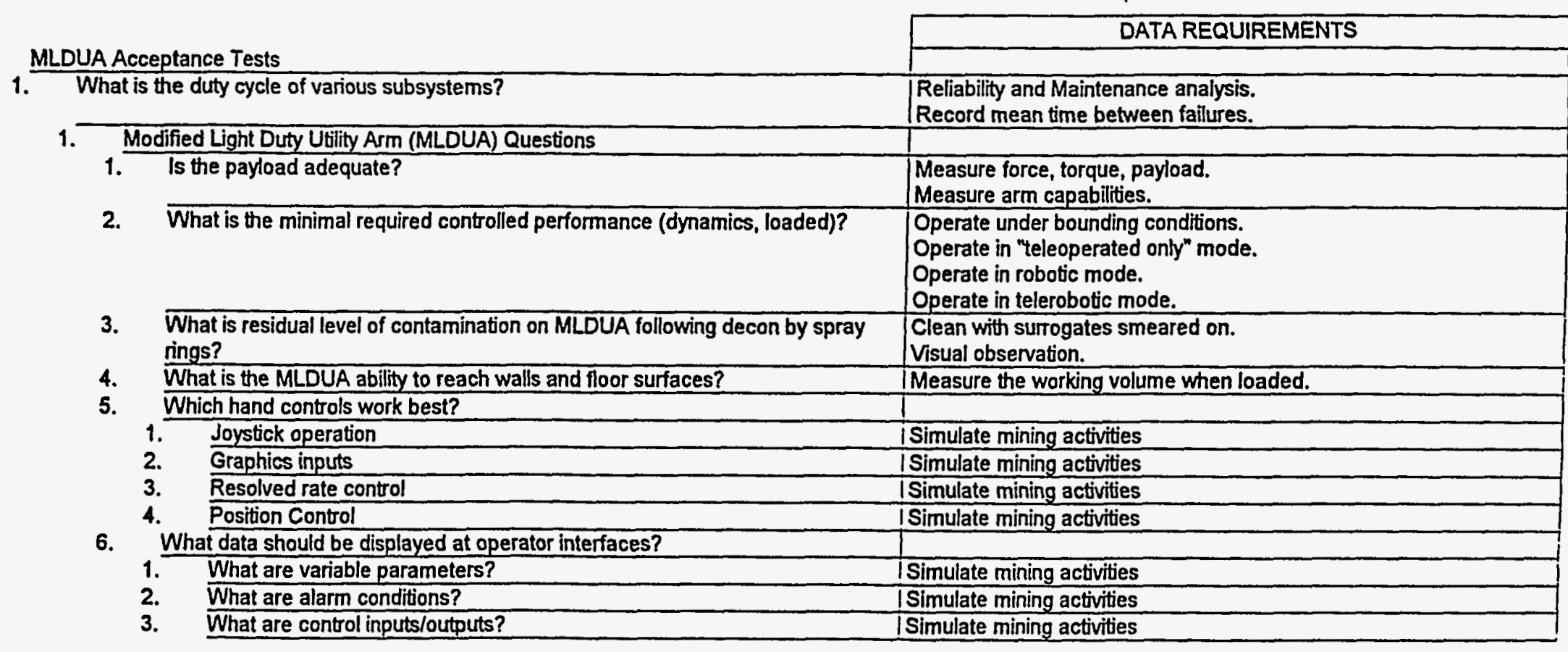


TRANSFER BOX FUNCTIONAL TESTS

Transfer Box Functional Test

1. What are mandatory spare parts inventories for each piece of equipment?

DATA REQUIREMENTS

What is the duty cycle of various subsystems?

Estimated life cycle for each component

Reliability and Maintenance analysis.

3. What is decon-ability of flow meter and transfer box components

Record mean time between failures.

flush flow meter, visual inspection

4. What is flow meter repeatability with multi-phase flow of air, water and simulated sludge?

5. What is flow meter accuracy with multi-phase flow of air, water and simulated sludge?

mass flow, and volumetric flow

Measure percent solids, viscosity,

mass flow, and volumetric flow 


\section{JET PUMP FUNCTIONAL TESTS}

Punctional Test

1. If pitch arm is 10 degrees beyond horizontal - will HMS arm swing out under its own

weight?

2. What are the dynamic and static loads associated with the WD\&C (affect on MLDUA)?

3. What are the affects of the transition between pumping air and pumping water?

\begin{tabular}{l}
\hline DATA REQUIREMENTS \\
\hline Similate activity \\
\hline Dynamic and static loads \\
Induce multi-phase flow and measure w/ \\
force/torque sensor. \\
Change in flow rate. \\
\hline Change in solids transfer \\
\hline \\
\hline Mock failure and demonstrate recovery \\
\hline Mock failure and demonstrate recovery \\
\hline Mock failure and demonstrate recovery \\
\hline Mock failure and demonstrate recovery \\
\hline Mock failure and demonstrate recovery \\
\hline Mock failure and demonstrate recovery \\
\hline Mock failure and demonstrate recovery \\
\hline Stop pump operation. Flush line. \\
Evaluate sludge remaining in line. \\
\hline Test jet pump debris handling ability w/out CSEE operation \\
\hline Develop procedures for unclogging-unplugging line \\
\hline
\end{tabular}

5. What is plugging potential for various forms of debris?

1. Test in simulated sludge w/sluicing

2. Test in simulated sludge w/out sluicing

4. How does the WD\&C recover from failures?

1. Power Loss

2. "E"-Kill

3. High pressure hydraulic line rupture

4. Plug in the line

5. Rupture conveyance line

6. Failed CSEE drive

7. Failed swivel joint

8. Broken cable

9. How does piping drain following pump failure?

6. What are line unplugging/unclogging procedures? 
WD\&C PERFORMANCE TESTS

WD\&C Performance Test

1. What is HMS range of motion in passive mode?

2. What is HMS range of motion in active mode?

3. How is maintenance performed for these failures?

1. High pressure hydraulic line rupture

2. Plug in the line

3. Rupture conveyance line

4. Failed CSEE drive

5. Failed swivel joint

6. Broken cable

4. Where will hot maintenance be performed?

5. Prevenvdetect line plugging

6. What are Retraction Procedures?

7. What are Deployment Procedures?

8. What is plugging potential for various forms of debris?

9. What are the control coordination requirements for the "Balance of Plant"

10. What are mandatory spare parts inventories for each piece of equipment?

11. Walk through all Hoisting and Rigging Procedures

12. Simulate making and breaking all connections

13. How will exposures be estimated for STF?

1. What is involved in moving from one riser to another in terms of personnel exposure?

14. What is involved in moving from one riser to another in terms of contamination control?

15. What is involved in moving from one riser to another in terms of time?

16. Modified Light Duty Utility Arm (MLDUA) Questions

1. What are the best viewing properties for mining operations?

What are the best viewing properties for mining operations?
1. Field of Vision
2. Zoom
3. Lighting
4. Lens Cleaning
5. Refractive Index
6. Focus

7. Áfiect of Supernate

2. What data should be displayed at operator interfaces? $--$

17. What are line unplugging/unclogging procedures?

-... - - - -

18. How does the WD\&C recover from failures?

Prediction of equipment maintenance requriements

radiation levels of equipment after exposure

Record number of events/ conditions

Simulate activities

Simulate activities

Test jet pump debris handling ability w/out CSEE operation

Simulate activities

Estimated life cycle for each component

\section{Perform radiation monitoring for TS}

demob/transport activities between risers.

Compare to theoretical calculated

exposures.

Collect time info for mob/demob between risers

Vary camera position, lighting and camera features

Vary camera position, lighting and camera features

Vary camera position, lighting and camera features

Vary camera position lighting and camera features ___ _ _ _

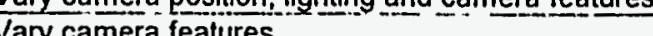

Vary camera features

ary camera position, lighting, and camera features

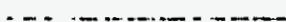




\section{WD\&C PERFORMANCE TESTS}

\begin{tabular}{|c|c|c|}
\hline \multirow[b]{3}{*}{1.} & \multirow[b]{3}{*}{ Power Loss } & \multirow[b]{2}{*}{ DATA REQUIREMENTS } \\
\hline & & \\
\hline & & \multirow{2}{*}{ Mock failure and demonstrate recovery } \\
\hline 2. & "E"-Kill & \\
\hline 3. & High pressure hydraulic line rupture & Mock failure and demonstrate recovery \\
\hline 4. & Plug in the line & Mock failure and demonstrate recovery \\
\hline 5. & Rupture conveyance line & Mock failure and demonstrate recovery \\
\hline 6. & Failed CSEE drive & Mock failure and demonstrate recovery \\
\hline 7. & Failed swivel joint & Mock failure and demonstrate recovery \\
\hline 8. & Broken cable & Mock failure and demonstrate recovery \\
\hline 9. & How does piping drain following pump failure? & \multirow{2}{*}{$\begin{array}{l}\text { Stop pump operation. Flush line. } \\
\text { Evaluate sludge remaining in line. } \\
\text { similate pumping and line flushing activities }\end{array}$} \\
\hline & $N$ does 45 degree angle offset in line affect material transfer? & \\
\hline & What are potential plugging challenges? & \multirow{3}{*}{$\begin{array}{l}\text { Note any buildup of solids in line after } \\
\text { flushing. } \\
\text { Test efficiency and effectiveness of CSEE } \\
\text { at varying distances; use SCEE w/o stand-off control }\end{array}$} \\
\hline & at tolerance is acceptable for CSEE stand-off distance? & \\
\hline & In water? & \\
\hline & In surrogate sludge? & \\
\hline \multicolumn{3}{|c|}{ Cost Questions } \\
\hline & Rate of equipment failure (or average time to failure) for each piece of equipment? & $\begin{array}{l}\text { Failure rate or average time to failure for each } \\
\text { piece of equipment and cost to replace } \\
\text { (costs assoociated with down time, } \\
\text { replacement of part, etc.) }\end{array}$ \\
\hline \multicolumn{2}{|r|}{ 2. What are the system start-up and shut-down costs? } & \multirow[b]{2}{*}{$\begin{array}{l}\text { Costs to begin operations (excluding capital costs) } \\
\text { Linear speed. } \\
\text { Coordinating tracking speed. } \\
\text { Develop equipment staging scenarios for } \\
\text { different types sludge. } \\
\text { Cone of influence. }\end{array}$} \\
\hline & at is the optimal mining strategy? & \\
\hline & For varying sludges? & $\begin{array}{l}\text { Linear speed } \\
\text { Coordinating tracking speed. } \\
\text { Develop equipment staging scenarios } \\
\text { different sludge types. } \\
\text { Cone of influence. }\end{array}$ \\
\hline \multicolumn{2}{|r|}{ What is the cost of performing waste removal? } & Collect actual costs in TS and extrapolate to STF. \\
\hline & $\begin{array}{l}\text { What is the cost for set-up and decontamination of equipment? } \\
\text { te Dislodging and Conveyance System Questions }\end{array}$ & Collect cost for initial selup and extrapolate to STF. \\
\hline & What is the WD\&C Performance in various sludge/supernate combinations & \multirow{2}{*}{$\begin{array}{l}\text { Establish boundary conditions } \\
\text { Simulate mining activities for various } \\
\text { simulated sludge densities }\end{array}$} \\
\hline 2. & What are the optimal mining strategies for each anticipated slurry/density rate? & \\
\hline
\end{tabular}




\section{WD\&C PERFORMANCE TESTS}

25. What is contamination level on WD\&C after decon?

DATA REQUIREMENTS

Clean with surrogates smeared on.

Visual Observation.

26. What is the change-out time for a new pump?

27. What is the changeout time for a new hose management system

28. What is the duty cycle of various subsystems?

Measure/observe simulant left on at end of cold test

Mock up maintenance activity in full dress-out

29. How much water is added per decon event?

1. Per tank deployment?

2. Per back flush?

30. How much water needs to be added per unit of waste removed?

Mock up maintenance activity in full dress-out

Reliability and Maintenance analysis.

Record mean time between failures.

Measure water used in decon.

Record number of times decon rings are activated.

Measure water used per event

Measure the water used per event

Record number of back flushes

Volume of motive water.

Volume of culting jet water.

Volume of slurry discharged.

31. How much sludge is removed per unit operating time?

Simulate boundary conditions.

Develop percent solids removed and

solids removed per operating time.

Extrapolate from TS to STF. 


\section{MLDUA PERFORMANCE TESTS}

MLDUA Performance Test

1. Verify control system enhancements

What are mandatory spare parts inventories for each piece of equipment?

3. Simulate Hoisting and Rigging Activities

4. Simulate Tank Deployment

5. Simulate MLDUA Retraction

6. Make and Break all connections

7. How will exposures be estimated for STF?

1. What is involved in moving from one riser to another in terms of personnel exposure?

8. What is involved in moving from one riser to another in terms of time?

9. Simulate purge system

10. Simulate end effector changeout

11. Characterization end effector questions

1. How do we calibrate initially and after hot deployment?

2. How many data points are enough statistically?

12. What is the anticipated exposure for equipment changeout?

13. What data should be displayed at operator interfaces?

1. What are control inputs/outputs?

14. Cost Questions

1. Rate of equipment failure (or average time to failure) for each piece of equipment?

15. Can MLDUA be used for tank wall, foor repair/ patching work?

16. Is the MLDUA needed for in-situ grouting or is a simpler/less costly method more viable?

17. What is the cost of performing waste removal?

1. What is the cost for set-up and decontamination of equipment?

2. What is involved in moving from one riser to another in terms of cost?

18. What is the duty cycle of various subsystems?

19. Modified Light Duty Utility Arm (MLDUA) Questions

\section{DATA REQUIREMENTS}

Estimated life cycle for each component

Perform radiation monitoring for TS

demob/transport activities between risers.

Compare to theoretical calculated

exposures.

Collect time info for mob/demob between risers

Simulate calibration routine for hot conditions

No. of data points required for documenting tank closure

Calculate theoretical exposure for equipment

changeout for TS.

Compare actuals to calcualted.

Calculate STF exposure based on percent error

of TS calcs

Simulate Mining Activities

Failure rate or average time to failure for each

piece of equipment and cost to replace

(costs assoociated with down time,

replacement of part, etc.)

Perform Feature Cold tests

Perform Feature Cold tests

Collect actual costs in $\mathrm{TS}$ and extrapolate to STF.

Collect cost for initial setup and extrapolate to STF - - - - -

Collect cost for mob/demob between risers

Collect cost for mob/demob belween risers ...... . .........

Reliability and Maintenance analysis.

Record mean time between failures. 


\section{MLDUA PERFORMANCE TESTS}

1. Is the payload adequate?

2. is the positioning accuracy adequate?

3. What is the minimal required controlled performance (dynamics, loaded)?

DATA REQUIREMENTS

Measure force, torque, payload.

Measure arm capabilities.

Measure positioning accuracy

Operate under bounding conditions.

Operate in "teleoperated only" mode.

Operate in robotic mode.

4. What is residual level of contamination on MLOUA following decon by spray rings?

Operate in telerobotic mode.

5. What is the MLDUA ability to reach walls and floor surfaces?

6. What is the MLDUA ability to maneuver around obstacles?

7. How does the MLDUA recover from failures?

1. "Power Loss

2. "E"-Kill

3. Hydraulic line rupture

4. Pneumatic line rupture

5. Mechanical break

6. "Boot" Failure

7. Control system failure

8. How is maintenance performed following these MLDUA failures?

1. Hydraulic line rupture

2. Pneumatic line rupture

3. Mechanical break

4. "Boot" Failure

5. Control system failure

9. How does the Gripper end effector recover from failures?

\section{Hydraulic line rupture}

3. Pneumatic line rupture

4. Mechanical break

5. Control system failure

10. How is maintenance performed following these gripper end effector failures?

1. Hydraulic line rupture

2. Pneumatic line rupture

3. Mechanical break

4. Control system failure

11. Which hand controls work best?

?

1. Joystick operation

3. Resolved rate control 
MLDUA PERFORMANCE TESTS

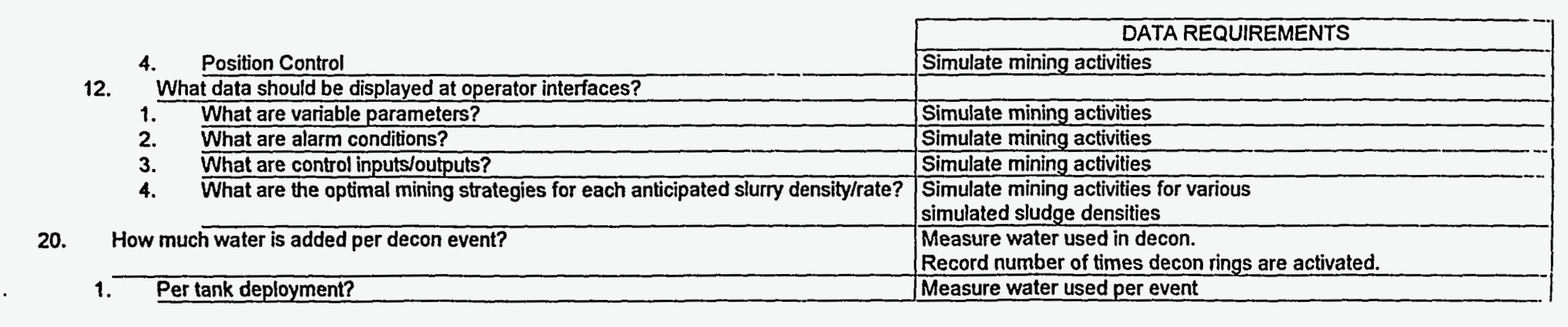




\section{INTEGRATED SYSTEM PERFORMANCE TESTS}

INTEGRATED SYSTEMS (IS) PERFORMANCE'TESTS

1. How do we determine that we are cleaning sludge/gunite surfaces? Monitor effluent for gunite.

2. What pressures are required to scabble the wall? Monitor video of tank wall for scouring

1. Will tank walls withstand scabble action?

2. How will damage to the tank be minimized?

3. What are the optimal CSEE set-up parameters for tank wall cleaning/scarifying? 1. nozzle angle?

2. nozzle size?

3. pressures and flow rates?

4. Simulate Procedures

5. What are the control coordination requirements for the "Balance of Plant"

6. Perform performance test of sampling system

7. Which riser is MLDUA moved to next?

8. Will MLDUA be moved to another riser?

9. Perform Mining Strategy with interactive Hose Management System

10. Perform Mining Strategy with Passive Hose Management System

11. Perform Integrated Control System Check Out

12. How much sludge is removed per unit operating time? Test scabble efficiency and effectiveness

at varying pressures and distances and on varying materials Determine final wall integrity? Document scarifying pressures

Measure cleaning efficiency and effectiveness

at varying angles

Measure percent solids in effluent

Measure cleaning efficiency and effectiveness

at varying nozzle sizes

Measure percent solids in effluent

Measure cleaning efficiency and effectiveness

at varying pressures

Measure percent solids in effluent

Simulate activities

Develop scenarios for each STF tank

ibased on NTF experience.

Develop scenarios for each STF tank

based on NTF experience.

i

Simulate boundary conditions.

Develop percent solids removed and

solids removed per operating time.

13. How much water needs to be added per unit of waste removed?

Extrapolate from TS to STF

Volume of motive water.

Volume of cutting jet water.

Volume of slurry discharged.

14. Waste Dislodging and Conveyance System Questions

Verified in Hot test.

1. What is the WD\&C Performance in various sludge/supernate combinations

(1)

What rad doses will be encountered durin

Document time spent working on potentia

"hot" equipment

16. What tolerance is acceptable for CSEE stand-off distance?

( efficiency and effectiveness of CSE 


\section{INTEGRATED SYSTEM PERFORMANCE TESTS}

In water?
How do we know when we are done with a tank?

17. How do we know when we are done with a tank?

18. How do we know when we are done at any one location in a tank?

DATA REQUIREMENTS

Visual Inspection

Solids Concentration

Pathway Document

\begin{tabular}{l|l} 
Visual inspection \\
Solids Concentration
\end{tabular}

19. Will transuranic waste remain in the tanks?

1. What will be the volume of sludge removed at completion of remediation?

Mon

Monitor drop in solids concentration.

Estimate quantity of residual sludge from photographs.

Final tank closure requirements

(removal, stabilization, etc.)

2. How much residual sludge will remain in the tanks after completion of remediation?

20. What is the cost of performing waste removal?

1. What is the cost for reusable equipment?

2. What is the cost for facility modification?

1. What is the cost of riser installation?

3. Are platforms needed?

Collect actual costs in TS and extrapolate to STF.

Collect actual costs in TS and extrapolate to STF.

Collect actual costs in TS and extrapolate to STF.

Collect actual costs in TS and extrapolate to STF.

4. Can we use existing platforms?

Loads that tank can bear.

Footprints of equipment.

Locations and conditions of risers to be used.

Loads that tank can bear.

Loads experienced by $W-3$ \& 4 in TS.

Footprints of equipment.

5. How much will platforms cost?

7. Can we use existing risers?

8. Do we need additional risers?

9. What is the cost to remove waste through existing risers?

10. What is the cost to remove waste through additional risers?

11. What is the cost to remove "all" sludge and begin removing gunite?

Locations and conditions of risers to be used. Collect actual costs

Collect cost for initial setup and extrapoiate to STF

Locations and conditions of risers to be used.

Diameters of risers needed.

Locations and conditions of risers needed.

Diameters of risers needed.

Collect cost for operation through at least

two risers

Estimate cost for riser installation from $\bar{T} \bar{s}$.

Collect cost for operation through at least

two risers.

Completely remove sludge from a tank.

Begin to scabble gunite. 


\section{INTEGRATED SYSTEM PERFORMANCE TESTS}

12. What is the cost to remove the gunite?

DATAREQUIREMENTS

Remove some gunite

Note percent solids and type solids

in pipeline and by video

13. What is involved in moving fiom one riser to another in terms of cost?

14. What is total setup time?

15. What is total system check-out time?

21. How do human factors affect operator duty cycles?

22. How much waste can we remove?

23. What is the optimal mining strategy?

\section{For varying sludges?}

24. Which tank riser does MLDUA enter first?

25. What is the duty cycle of various subsystems?

26. Can tank wall integrity withstand 11,000 psi from grout injection/mixing?

27. Modified Light Duty Utility Arm (MLDUA) Questions

1. What is the effect of friction of the CSEE against a surface on arm performance?

2. What is affect of hose management system?

Collect cost for mob/demob between risers

Collect cost for operation through at least

two risers

Collect information for checkout time for

both tanks in TS

Perform Human Factors Evaluation

Linear speed.

Coordinating tracking speed.

Develop equipment staging scenarios for

different types sludge.

Cone of influence.

Linear speed

Coordinating tracking speed.

Develop equipment staging scenarios

different sludge types.

Cone of influence.

Develop scenarios for each STF tank

based on NTF experience.

Reliability and Maintenance analysis.

Record mean time between failures.

Perform scarification tests

\section{What data should be displayed at operator interfaces?}

1. What are the optimal mining strategies for each anticipated slurry density/rate?

28. How many operators are needed?

29. Cost Questions

1. Rate of equipment failure (or average time to failure) for each piece of equipment?

Measure positioning requirements and speed,

control requirements during cold tests

Note hose management system effect on

mining strategy

Simulate mining activities for various

simulated sludge densities

Perform Human Factors Evaluation

Failure rate or average time to failure for each

piece of equipment and cost to replace

$i$ (costs assoociated with down time,

2. What are the system start-up and shut-down costs?

ireplacement of part. etc.)

3. What are the estimated PPE costs per day of operation?

Costs to begin operations (excluding capital costs) - - . ... 


\section{NTF OPERATIONS}

NTF OPERATIONS

1. Is the MLDUA needed for in-situ grouting or is a simpler/less costiy method more viable?

2. How will damage to tank be minimized?

3. Hot Test

1. Site Specific Health and Safety Plan

2. Conduct of Operations Assessment Summary Report

3. Instrument calibration

4. Traffic Control Plan

5. Operations Procedures

6. Safety Work Permit

7. Waste Management Plan

8. Evidence of required LMES training

9. Evidence of required hot test specific training

10. Pressure safety compliance

11. NEPA approval

12. Davis-Bacon Ruling

13. Project Management Plan

14. Release from ORNL HP that there are no radiological concerns for this test

15. Project Safety Assessment

16. QA Project Plan

17. Configuration Management Plan

18. Hoisting and Rigging Plan

19. Decontamination of Equipment Plan

4. How much waste can we remove?

5. What pressures are required to scabble the wall?

1. Will tank walls withstand scabble action?

2. How will damage to the tank be minimized?

6. What tolerance is acceptable for CSEE stand-off distance?

\section{In water?}

2. In surrogate sludge?

7. What is the cone of influence of pumping action in simulated sludge?

1. In sludge w/ s.g. of 1.9

2. In several different sludge consistencies

Perform Feature Cold tests

Document scarifying pressures

\begin{tabular}{|l|}
\hline \\
\hline \\
\hline \\
\hline \\
\hline \\
\hline \\
\hline \\
\hline \\
\hline Test scabble efficiency and effectiveness \\
\hline at varying pressures and distances and on varying materials \\
\hline Determine final wall integrity? \\
\hline Document scanifying pressures \\
\hline $\begin{array}{l}\text { Test efficiency and effectiveness of CSEE } \\
\text { at varying distances; use SCEE w/o stand-off control }\end{array}$ \\
\hline \\
\hline Height and depth of cone of influence \\
\hline Measure path
\end{tabular}




\section{NTF OPERATIONS}

8. What is the anticipated exposure for equipment changeout?

DATA REQUIREMENTS

Calculate theoretical exposure for equipment changeout for TS.

Compare actuals to calcualted.

Calculate STF exposure based on percent error of TS calcs

9. How do we determine that we are cleaning sludge/gunite surfaces?

Monitor effluent for gunite.

Monitor video of tank wall for scouring

10. What is contamination level on WD\&C after decon? Clean with surrogates smeared on.

Visual Observation.

Measure/observe simulant left on at end of cold test

11. How much water will be added per unit of sludge removed?

Gallons of water added during sludge removal

12. Cost Questions

1. Rate of equipment failure (or average time to failure) for each piece of equipment? Failure rate or average time to failure for each piece of equipment and cost to replace

(costs assoociated with down time.

2. What are the system start-up and shut-down costs?

replacement of part. etc.)

3. What are the estimated PPE costs per day of operation?

Costs to begin operations (excluding capital costs)

Total cost of PPE for all field personnel

many people will be used? What is predicted tum-over ratio?

'Training requirements for all personnel involved,

number of people to be trained.

5. What are the costs associated with additional equipment and parts? No. of additional parts to be stocked during the project, turn-over ratio cost for each piece

6. What are the demobilization and equipment storage costs?

How to store, where to store, costs of storage

7. What are project management costs? !Internal costs for personnel time,

facility and equipment

accounting costs, travel costs, etc. and

8. What are the sampling costs?

contractor costs for project management

Number of samples, analytical requirements,
turn around time, sample shipment costs,

sampling equipment costs

9. What are the consulting costs? IRequired plans (health and safety, etc.), cost to

prepare, TS personnel,

regulatory meetings, etc.

10. What are the reporting costs?

review costs. photcopying costs.

shipping costs

11. What are the meeting costs?

Number of meetings required, persons in

attendance, time for meetings, cost for

persons 


\section{NTF OPERATIONS}

13. What is the concentration of radioactive and RCRA components in the concrete after remediation?

14. Will RCRA and/or radioactive components in the sludge that is transferred to MVST leach into the supemate?

15. Are RCRA components in the final waste form leachable?

16. Are the radioactive components ( $\mathrm{Sr}, \mathrm{Cs}$, TRU, etc.) in the slumy sludges leachable?

17. What velocity is needed to maintain solids in suspension for pipeline transfer to MVST?

18. How much do the sludge radiation levels vary across sludge in the tanks?

19. What is the settling rate of the sluiced sludge?

20. What is the water content of the sludge after sluicing?

21. How uniform is the sludge in each tank?

22. What are the physical characteristics of the sludge in W-3 and W-4? Particle theology

before and after sluicing?

23. Can tank wall integrity withstand 11,000 psi from grout injection/mixing?

24. How will debris be handled?

25. What is waste's thermal value?

26. Does the waste contain Beryllium? How many grams?

27. What is the estimated weight percent of combustibles?

28. is waiver needed to transfer PCBs> 2 ppm to MVSTs? (TSCA in effect only for $>50$

ppm).

29. Are all the TSCA-regulated constituents identified?

30. Are all EPA waste codes identified along with the RCRA constituents that caused the waste code to be applied?

31. What are the size and weight percent of the particulates in dried sludge? (weight $\%<10$ um and $<200 \mathrm{um}$ )

32. Does waste contain anything prohibited by the storage or disposal site? (e.g. pyrophorics, ignition sources, explosives, chelating agents, etiological agents, EPA characteristics of ignitability, corrosivity, or reactivity)

33. Will waste be Contact Handied-TRU or Remote Handled-TRU? (function of storage site, Verify validity of current data in TS. waste form. packaging)

34. Are waivers for ceratin key items (e.g., free liquids, small particulate) worth pursuing?

35. What are the erosion/corrosion potentials of the piping?

36. Are there any other waste characteristics which would cause processing problems or exposure?

37. Is there evidence to justify or document why the sludges in all of the GAAT do not have more consistent distribution of radionuclides?
DATA REQUIREMENTS

Collect wall samples at end of TS.

ith MVST I supernate. perform TCLP test. TCLP test of sludges.

TCLP test of sludges.

Verify in TS.

'Collect in-line samples, use characterization end-effector

Collect in-line samples

Collect in-line samples

Collect in-line samples

Collect in-line samples

Perform scarification tests

Characterize types of debris to be encountered

Verify validity of current data in TS.

Verify validity of current data in TS.

Verify validity of current data in TS.

What is concentration of PCBs detected?

-Verify validity of current data in TS.

- Verify validity of current data in TS.

Collect particle size distribution.

Small particles are an airborne concern.

- Verify validity of current data in TS. 


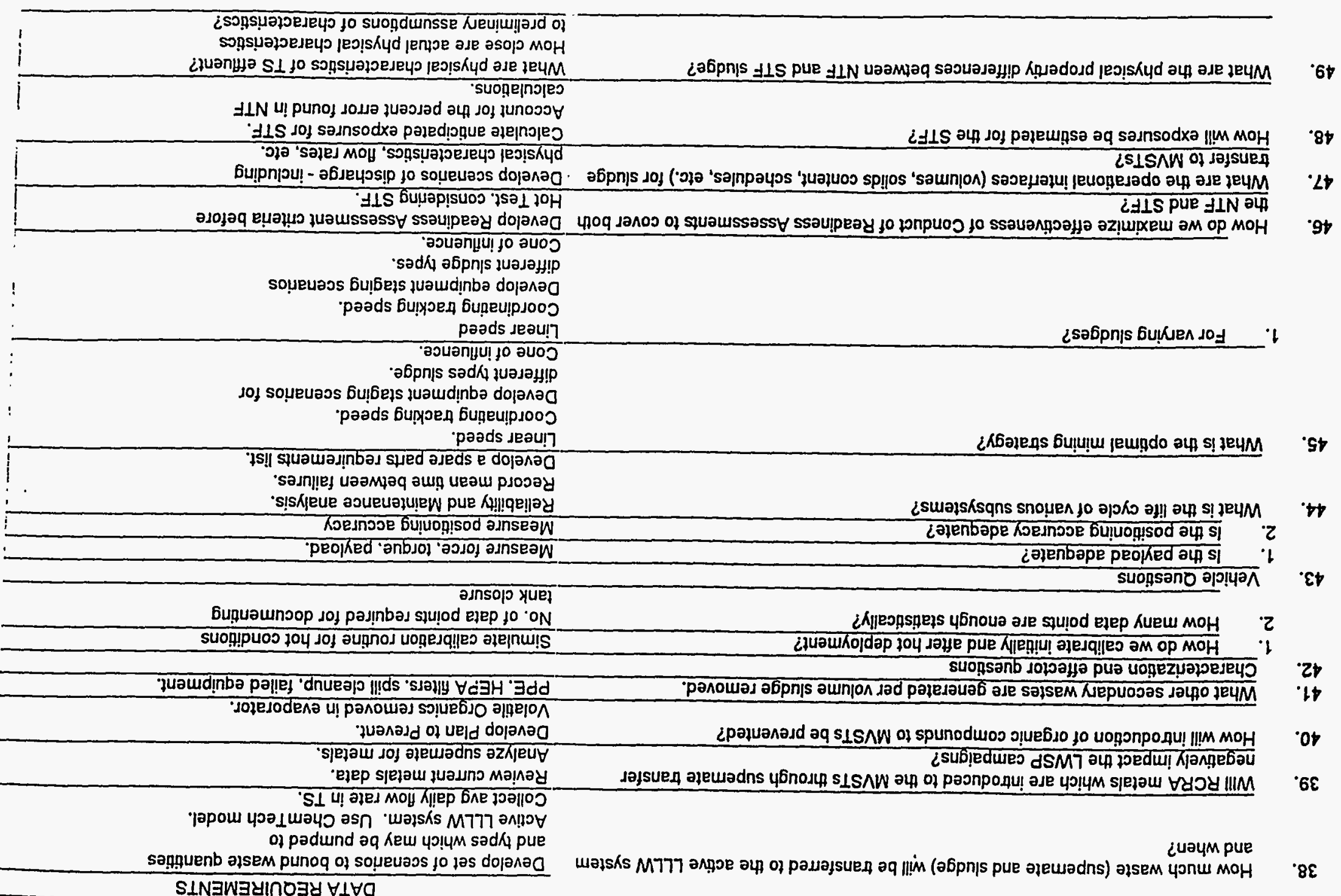

\section{SNOILVAIDO HIN}




\section{NTF OPERATIONS}

50. How do we know when we are done with a tank?

Visual Inspection

Solids Concentration

Pathway Document

51. How do we know when we are done at any one location in a tank?

Solids Concentration

52. Which tank riser does MLDUA enter first?

Develop scenarios for each STF tank

based on NTF experience.

53. Which tank nozzle do we put the equipment in first?

Develop scenarios for each STF tank

54. How much waste do we remove?

based on NTF experience.

55. How will exposures be estimated for STF?

1. What is involved in moving from one riser to another in terms of personnel exposure?

Information from pathway analysis.

Monitor volume remaining with cameras.

2. What are shielding requirements for STF?

Perform radiation monitoring for TS

demob/transport activities between risers.

Compare to theoretical calculated

exposures.

Calculate anticipated exposures for STF.

Account for the percent error found in NTF

calculations.

Plan for Shielding requirements accordingly.

56. What is involved in moving from one riser to another in terms of time?

Collect time info for mob/demob between risers

57. How many operators are needed?

58. How do human factors affect operator duty cycles?

Perform Human Factors Evaluation

59. When are we done?

Porform Human Factors Evaluation

Visual inspection.

Radiation surveys. WAC compliance.

Solids concentration.

Residual concentration.

Pathway Document

60. What is the duty cycle of various subsystems?

Reliability and Maintenance analysis.

Record mean time between failures.

1. Modified Light Duty Utilty Arm (MLDUA) Questions

1. Is the payload adequate? Measure force, torque, payload.

Measure arm capabilities.

3. What is the minimal required controlled performance (dynamics, loaded)? Operate under bounding conditions.

Operate in "teleoperated only" mode.

Operate in robotic mode.

Operate in telerobotic mode.

4. What is residual level of contamination on MLDUA following decon by spray Clean with surrogates smeared on. rings? Visual observation. 


\section{NTF OPERATIONS}

5. What is the MLDUA ability to reach walls and floor surfaces?

6. What is the MLDUA ability to maneuver around obstacles?

7. How does the MLDUA recover from failures?

1.
2. Power Loss
3. How -Kill
4. Pydraulic line rupture
5. Mecumatic line rupture
6. "Bochanical break
7. Control system failure

What are the best viewing properties for mining operations?

1. Field of Vision Vary camera position, lighting and camera features

2. Zoom Vary camera position, lighting and camera features

3. Lighting Vary camera position, lighting and camera features

4. Lens Cleaning :Vary camera position, lighting and camera features

5. Refractive Index Vary camera features

6. Focus $\quad$ Vary camera features

7. Affect of Supemate Vary camera position. lighting, and camera features

9. What is the effect of friction of the CSEE against a surface on arm ; Measure positioning requirements and speed, performance? $\quad$ icontrol requirements during cold tests

10. What is affect of hose management system? Note hose management system effect on

\begin{tabular}{l|l} 
11. How is maintenance performed following these MLDUA failures? & mining strategy \\
\hline
\end{tabular}

1. Hydraulic line nupture

2. Pneumatic line rupture

3. Mechanical break

4. "Boot" Failure

5. Control system failure

12. How does the Gripper end effector recover from failures?

1. Powertoss

2. Hydraulic line rupture

3. Pneumatic line rupture

4. Mechanical break

5. Control system failure

13. How is maintenance performed following these gripper end effector failures?

1. Hydraulic line nupture

2. Pneumatic line rupture

3. Mechanical break

4. Control system failure

14. Which hand controls work best? 


\section{NTF OPERATIONS}

1. Joystick operation
2. Graphics inputs
3. Resolved rate control
4. Position Control
What data should be displayed at operator interfaces?
1. What are variable parameters?
2. What are alarm conditions?
3. What are control inputs/outputs?
4. What are the optimal mining strategies for each anticipated slumy
density/rate?

61. How much water is added per decon event?

\begin{tabular}{l}
\hline DATA \\
\hline Simulate mining activities \\
Simulate mining activities \\
Simulate mining activities
\end{tabular}

\section{DATA REQUIREMENTS}

Simulate mining activities

Simulate mining activities

Simulate mining activities

Simulate mining activities

Simulate mining activities for various

simulated sludge densities

Measure water used in decon

Record number of times decon rings are activated.

1. Per tank deployment?

2. Per back flush?

62. Can Record number of back flushes

What is "Balance of Plant" for South Tank Farm?

What are physical characteristics of effluent?

What is the continuituy of pumping streams

(rates, volumes)?

63. How much water needs to be added per unit of What are settling characteristics of effluent?

Volume of motive water.

Volume of cutting jet water.

Volume of slurry discharged.

Verified in Hot test.

64. How much sludge is removed per unit operating time? I Simulate boundary conditions.

Develop percent solids removed and

solids removed per operating time.

Extrapolate from TS to STF

65. What is the Human Health Risk of the tank contents?

1. What is the volume of sludge in the tanks?

Extrapolate results of TS to STF

Flow sensor readings

Percent solids readings

2. What is the concentration of Radionuclides?

Extrapolate results of TS to STF.

3. What is the mobility of the radionuclides in the sludge?

4. What risk reduction can be achieved by sludge removal?

66. What is the cost of performing waste removal?

1. What is the cost for reusable equipment? 


\section{NTF OPERATIONS}

2. What is the cost for facility modification?

DATA REQUIREMENTS

1. What is the cost of riser installation?

Collect actual costs in TS and extrapolate to STF.

3. Are platforms needed?

Collect actual costs in TS and extrapolate to STF.

Loads that tank can bear.

Footprints of equipment.

Locations and conditions of risers to be used.

4. Can we use existing platforms?

Loads that tank can bear.

Loads experienced by $W-3$ \& 4 in TS.

Footprints of equipment.

Locations and conditions of risers to be used.

5. How much will platforms cost?

Collect actual costs

6. What is the cost for set-up and decontamination of equipment?

Collect cost for initial setup and extrapolate to STF.

7. Can we use existing risers?

Locations and conditions of risers to be used

Diameters of risers needed.

8. Do we need additional risers? Locations and conditions of risers needed.

9. What is the cost to remove waste through existing risers?

Diameters of risers needed.

10. What is the cost to remove waste through additional risers?

Collect cost for operation through at least

two risers

What is the cost to remove waste through additional risers? Estimate cost for riser installation from TS.

Collect cost for operation through at least

two risers.

11. What is the cost to remove "all" sludge and begin removing gunite?

Begin to scabble gunite.

12. What is the cost to remove the gunite? Remove some gunite

Note percent solids and type solids

in pipeline and by video

13. What is involved in moving from one riser to another in terms of cost? Collect cost for mob/demob between risers

14. What is total setup time? Collect cost for operation through at least

15. What is total system check-out time? two risers

Collect information

67. Will transuranic waste remain in the tanks?

1. What will be the volume of sludge removed at completion of remediation?

Monitor drop in solids concentration.

Estimate quantity of residual sludge from photographs.

Final tank closure requirements

(removal, stabilization, etc.)

2. How much residual sludge will remain in the tanks after completion of remediation?

3. What is the concentration of transuranic constituents in the residual sludge?

4. What is the concentration of tansuranic constituents in the gunite?

Perform analysis of last "pass" of sluicing head.

Perform analyses on gunite removed using the sluicing head. 

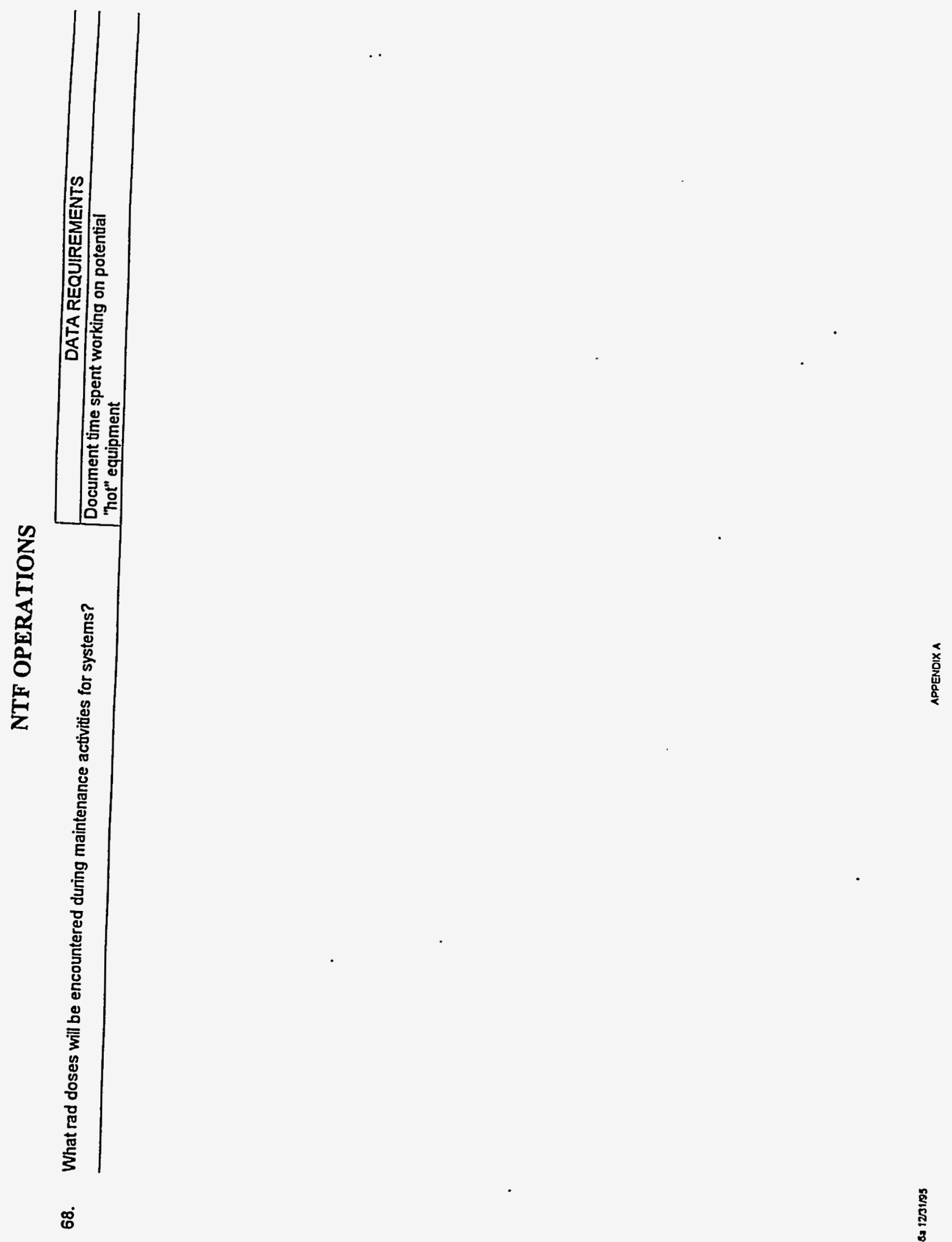


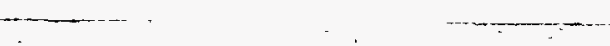

$\ldots$

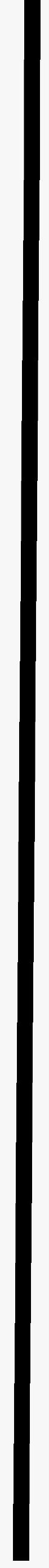




\section{EXISTING INFORMATION}

EXISTING INFORMATION

1. What is the life cycle of various subsystems? Reliability and Maintenance analysis.

Record mean time between failures.

Develop a spare parts requirements list.

2. What are MVST Waste Acceptance Criteria? - Develop scenarios of discharge - including

'physical characteristics, flow rates, etc.

3. What volume of sludge is available for use in ex-situ grouting and vitrification

demonstrations?

4. Are RCRA components in the final waste form leachable?

TCLP test of sludges.

5. Are the radioactive components ( $\mathrm{Sr}, \mathrm{Cs}$. TRU, etc.) in the slumy sludges leachable? TCLP test of siudges.

6. What is waste's thermal value?

7. Does the waste contain Beryllium? How many grams?

8. What is the estimated weight percent of combustibles?

9. Is waiver needed to transfer PC8s> 2 ppm to MVSTs? (TSCA in effect only for $>50$ ppm).

10. Are all the TSCA-regulated constituents identified?

11. Are all EPA waste codes identified along with the RCRA constituents that caused the, Verify validity of current data in TS.

12. What are the size and weight percent of the particulates in dried sludge? (weight \%<10 Collect particle size distribution.

$\begin{array}{ll}\text { um and }<200 \mathrm{um} \text { ) } & \text { Small particles are an airborne concem. }\end{array}$

13. Does waste contain anything prohibited by the storage or disposal site? (e.g., Verify validity of current data in TS.

pyrophorics, ignition sources, explosives, chelating agents, etiological agents, EPA

characteristics of ignitability, corrosivity, or reactivity)

14. Will waste be Contact Handled-TRU or Remote Handled-TRU? (function of storage site, Verify validity of current data in TS. waste form, packaging)

15. Are waivers for ceratin key items (e.g., free liquids, small particulate) worth pursuing? Collect particle size distribution.

I Small particles are an airborne concern.

16. Are there any other waste characteristics which would cause processing problems or Consider in design phase. exposure?

Consider in design phase.
Operator logs to note any occurences.

17. Is there evidence to justify or document why the sludges in all of the GAAT do not have a iReview current data. more consistent distribution of radionuclides?

18. How much waste (supemate and sludge) will be transferred to the active LLLW system Develop set of scenarios to bound waste quantities and when?

and types which may be pumped to

Active LLLW system. Use ChemTech model.

Collect avg daily flow rate in TS.

19. Will RCRA metals which are introduced to the MVSTs through supernate transfer

negatively impact the LWSP campaigns?

20. How will introduction of organic compounds to MVSTs be prevented? Develop Plan to Prevent. Analyze supernate for metals.

21. Where will equipment be stored between hot test and remedial action?

22. Where will spare parts be stored?

Volatile Organics removed in evaporator.

Punteco 8 19a 1:3.195

Location information

Location information 


\section{EXISTING INFORMATION}

DATA REQUIREMENTS

23. What are mandatory spare parts inventories for each piece of equipment? Estimated life cycle for each component

24. Where will hot maintenance be performed? Prediction of equipment maintenance requriements

25. Characterization end effector questions

1. How many data points are enough statistically? radiation levels of equipment after exposure

26. What is the operating rate of an Out-of-Tank evaporator?

27. What is the operating rate of an in-Tank evaporator?

28. What is operating rate of the main plant evaporator?

29. What are the operational interfaces (volumes, solids content, schedules, etc.) for sludge transfer to MVSTs?

30. How will exposures be estimated for the STF?

No. of data points required for documenting

tank closure

Operating Rate

Operating Rate

Operating Rate

Develop scenarios of discharge - including

physical characteristics, flow rates, etc.

Calculate anticipated exposures for STF.

Account for the percent error found in NTF

calculations.

31. What are the physical propertiy differences between NTF and STF sludge? What are physical characteristics of TS effiuent?

How close are actual physical characteristics

to preliminary assumptions of characteristics?

32. How will exposures be estimated for STF?

1. What is involved in moving from one riser to another in terms of personnel exposure?

\section{Perform radiation monitoring for TS} demob/transport activities between risers.

Compare to theoretical calculated

33. Which tank riser does MLDUA enter first? exposures.

- Develop scenarios for each STF tank based on NTF experience.

34. Which tank nozzle do we put the equipment in first?

Develop scenarios for each STF tank

: based on NTF experience.

35. How many operators are needed?

36. What is the best sludge surrogate for Cold Tests?

37. What is the cost of performing waste removal?

1. What is the cost to remove waste through additional risers?

Perform Human Factors Evaluation

Physical properties. Expert consultation

Collect actual costs in TS and extrapolate to STF

Estimate cost for riser installation from TS.

Collect cost for operation through at least

two risers.

38. What is the Human Health Risk of the tank contents?

1. What is the volume of sludge in the tanks?

Compare sludge mapping to actuals.

Extrapolate results of TS to STF

Flow sensor readings

2. What is the concentration of Radionuclides?

Percent solids readings

3. What is the mobility of the radionuclides in the sludge?

Compare current data to actual TS data.

Extrapolate results of TS to STF.

Compare calculated diffusion coefficient $(K d)$

to actuals in TS 


\section{PRE-NTF OPERATIONS QUESTIONS}

PRE-OPERATIONS TEST

1. Where will equipment be stored between hot test and remedial action?

DATA REQUIREMENTS

2. Hot Test

1. Site Specific Health and Safety Plan

2. Conduct of Operations Assessment Summary Report

3. Instrument calibration

4. Traffic Control Plan

5. Operations Procedures

6. Safety Work Permit

7. Waste Management Plan

8. Evidence of required LMES training

9. Evidence of required hot test specific training

10. Pressure safety compliance

11. NEPA approval

12. Davis-Bacon Ruling

13. Project Management Plan

14. Release from ORNL HP that there are no radiological concerns for this test

15. Project Safety Assessment

16. QA Project Plan

17. Configuration Management Plan

18. Hoisting and Rigging Plan

19. Decontamination of Equipment Plan

3. What are MVST Waste Acceptance Criteria?

4. Cost Questions

1. What are the costs associated with additional equipment and parts?

2. What are the capital costs for the TS?

Locationinformation

Location information

How do we maximize effectiveness of Conduct of Readiness Assessments to cover both the NTF and STF?

6. What are the operational interfaces (volumes, solids content, schedules, etc.) for sludge transfer to MVSTs?

7. How will exposures be estimated for the STF?

8. Which tank riser does MLDUA enter first?

Develop scenarios of discharge - including physical characteristics, flow rates, etc.

9. Which tank nozzle do we put the equipment in first?

No. of additional parts to be stocked during the project cost for each piece

Construction costs, spare parts costs

based on NTF experience. 


\section{PRE-NTF OPERATIONS QUESTIONS}

10. How much waste do we remove?

\section{DATA REQUIREMENTS}

Information from pathway analysis.

Monitor volume remaining with cameras.

11. How will exposures be estimated for STF?

Perform radiation monitoring for TS

1. What is involved in moving from one riser to another in terms of personnel

exposure?

demob/transport activities between risers.

Compare to theoretical calculated

exposures.

\begin{tabular}{l|l|l} 
2. What are shielding requirements for STF? & Calculate anticipated exposures for STF
\end{tabular}

Account for the percent error found in NTF

calculations.

Plan for Shielding requirements accordingly.

12. What is the cost of performing waste removal?

I Collect actual costs in TS and extrapolate to STF.

1. What is the cost for facility modification?

1 Collect actual costs in TS and extrapolate to STF.

1. What is the cost of riser installation?

Collect actual costs in TS and extrapolate to STF.

2. Are platforms needed?

Loads that tank can bear.

Footprints of equipment

3. How much will platforms cost?

Locations and conditions of risers to be used.

4. What is the cost for set-up and decontamination of equipment?

Collect actual costs

Collect cost for initial setup and extrapolate to STF. 
PRE-REMEDLAL ACTION QUESTIONS

PRE-RA

DATA REQUIREMENTS

1. Hot Test

1. Site Specific Health and Safety Plan

2. Conduct of Operations Assessment Summary Report

3. Instrument calibration

4. Traffic Control Plan

5. Operations Procedures

6. Safety Work Permit

7. Waste Management Plan

8. Evidence of required LMES training

9. Evidence of required hot test specific training

10. Pressure safety compliance

11. NEPA approval

12. Davis-Bacon Ruling

13. Project Management Plan

14. Release from ORNL HP that there are no radiological concerns for this test

15. Project Safety Assessment

16. QA Project Plan

17. Configuration Management Plan

18. Hoisting and Rigging Plan

19. Decontamination of Equipment Plan

2. What are MVST Waste Acceptance Criteria?

3. Which lank riser does MLDUA enter first?

Develop scenarios of discharge - including

I physical characteristics. flow rates, etc.

Develop scenarios for each STF tank

based on NTF experience.

4. What are the operational interfaces (volumes, solids content, schedules, etc.) for sludge /Develop scenarios of discharge - including

5. How will exposures be estimated for STF?

1. What is involved in moving from one riser to another in terms of personnel exposure?

physical characteristics. flow rates, etc.

Perform radiation monitoring for TS

demob/transport activities between risers.

Compare to theoretical calculated

2. What are shielding requirements for STF?

exposures.

Calculate anticipated exposures for STF.

Account for the percent error found in NTF

calculations.

Plan for Shielding requiremènts accordingly.

6. How do we maximize effectiveness of Conduct of Readiness Assessments to cover both Develop Readiness Assessment criteria before

the NTF and STF? $\quad$ Hot Test. considering STF.

7. What are mandatory spare parts inventories for each piece of equipment? $\quad$ Estimated life cycle for each component

8. What is the cost of performing waste removal? iCollect actual costs in TS and extrapolate to STF. 


\section{PRE-REMEDLAL ACTION QUESTIONS}

1. Can we use existing platforms?

2. Can we use existing risers?

3. Dowe need additional risers?

9. Which tank nozzle do we put the equipment in first?

10. Are there any other waste characteristics which would cause processing problems or exposure?

11. How much waste do we remove?

12. Cost Questions

1. What are waste disposal costs (per unit of waste)?

2. What are the waste transporation costs (per unit of waste)?

3. What, if any, is the waste pre-treatment cost (per unit of waste)?

4. What is the initial training costs for operators and other project personnel? How many people will be used? What is predicted turn-over ratio?

5. What are the costs associated with additional equipment and parts?

6. What are the costs associated with waste transfer to MSVT?

\section{DATA REQUIREMENTS}

Loads that tank can bear.

Loads experienced by $W-3$ \& 4 in TS.

Footprints of equipment.

Locations and conditions of risers to be used.

Locations and conditions of risers to be used.

Diameters of nisers needed.

Locations and conditions of risers needed.

Diameters of risers needed.

Develop scenarios for each STF tank

based on NT.F experience.

Consider in design phase.

Operator logs to note any occurences.

Information from pathway analysis.

Monitor volume remaining with cameras.

\section{The cost for each type of waste (liquid,}

solids. used PPE. failed equipment, etc.

Method of trtansportation, cost per unit of

waste transported

Pre-treatment method and costs

Training requirements for all personnel involved

number of people to be trained.

turn-over ratio

No. of additional parts to be stocked during the project,

cost for each piece

Capital costs for connection, pumping cost, fees

levied by MVST. line unplugging costs, etc. 
APPENDIX C

TESTING ACTIVITIES SCHEDULE 



\section{GAAT TREATABILITY STUDY OPERATIONAL TESTING PROGRAM}

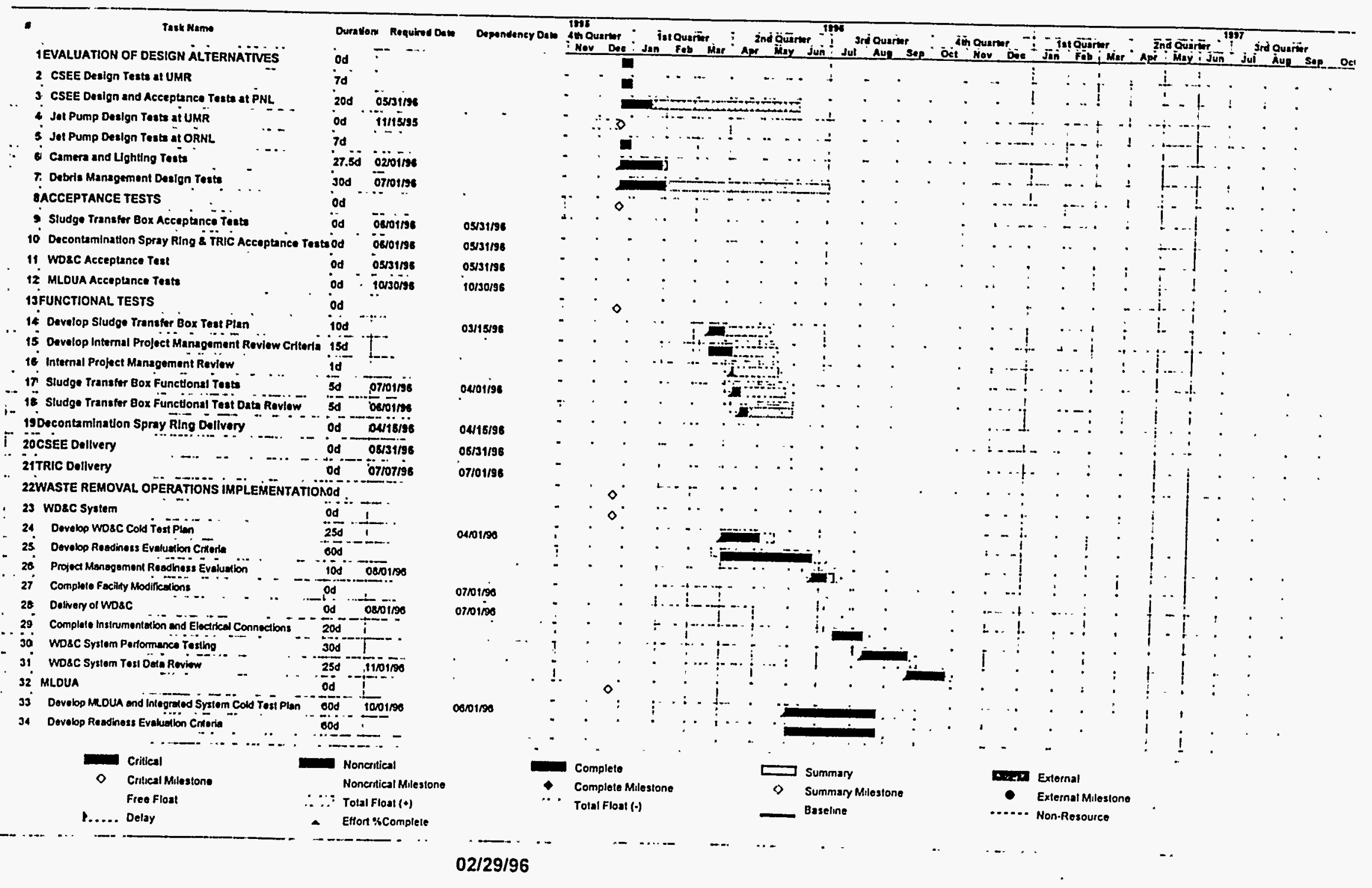




\section{GAAT TREATABILITY STUDY OPERATIONAL TESTING PROGRAM}

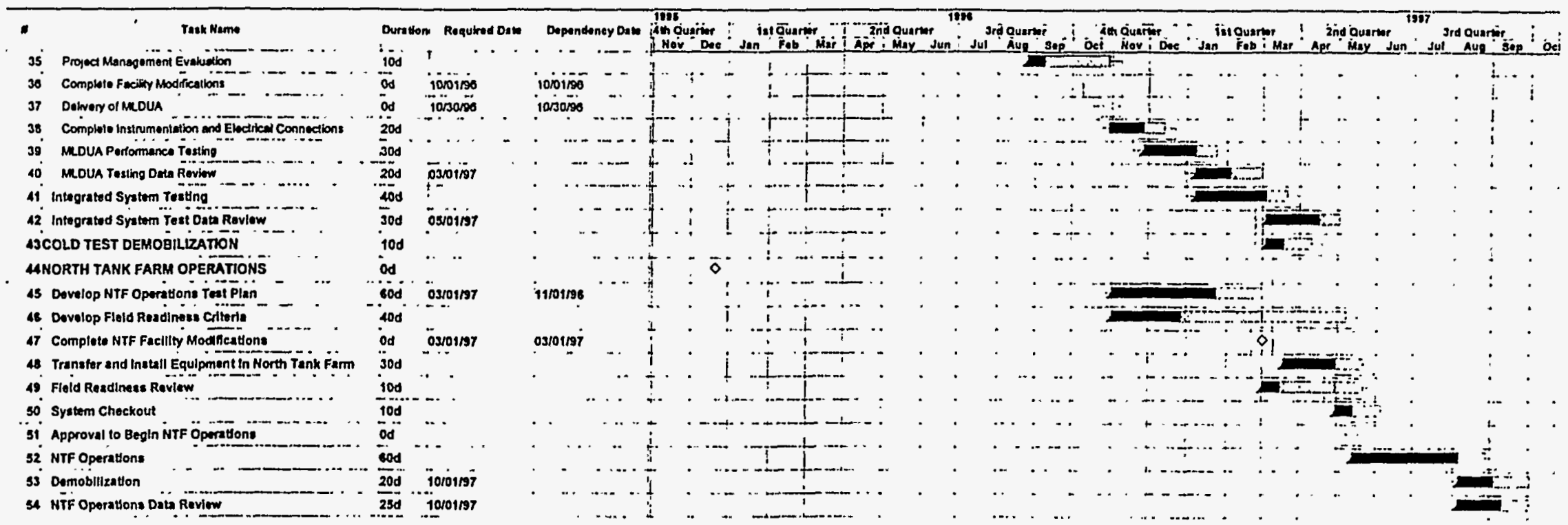

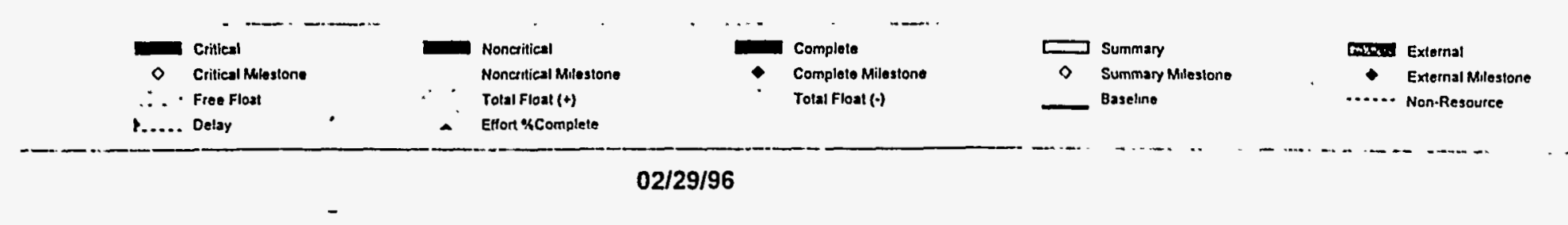




\section{DISTRIBUTION}

1. L. V. Asplund

2. J. Blank

3. B. L. Burks

4. D. Falter

5. R. L. Glassell

6. O.W. Hale

7. L. S. Hawk

8. L. Holder

9. M. A. Johnson

10. P. D. Lloyd

11-12. D. M. Matteo

13-14. P. T. Owen

15. J. H. Platfoot

16. J. D. Randolph

17. J. Rutenber

18. P. A. Schrandt

19. C. H. Scott

20. J. L. Snyder

21. W. T. Thompson

22-31. S. D. Van Hoesen

32. Central Research Library

33. ER Document Management Center-RC

34. Office of Scientific and Technical Information, P.O. Box 62, Oak Ridge, TN, 37831

35-38. B. A. Frederick, STEP Solutions to Environmental Problems, 1009 Commerce Park Drive Suite 400, Oak Ridge, TN 37830

39. C. O. Wiles, Parsons Infrastructure and Technology, 1055 Commerce Park Drive Suite 200, Oak Ridge, TN 37830

40-41. V. Rule, XI Associates, 677 Emory Valley Road, Suite C, Oak Ridge, TN 37830

42. N. Durfee, Science Applications International Corporation, 800 Oak Ridge Turnpike, Oak Ridge, TN 37831 


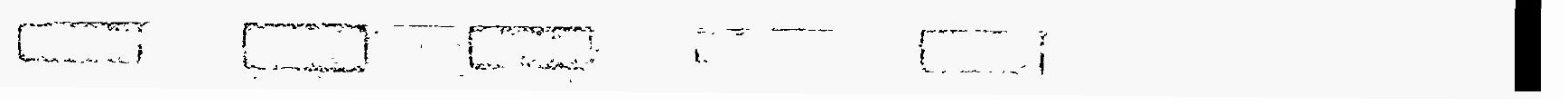

